\title{
Evidence of the gastroprotective and anti- Helicobacter pylori activities of $\beta$-mangostin isolated from Cratoxylum arborescens (vahl) blume
}

This article was published in the following Dove Press journal:

Drug Design, Development and Therapy

I3 January 2016

Number of times this article has been viewed

\author{
Heyam Mohamed Ali \\ Sidahmed' \\ Najihah Mohd Hashim' \\ Syam Mohan² \\ Siddig Ibrahim Abdelwahab ${ }^{2}$ \\ Manal Mohamed Elhassan \\ Taha $^{2}$ \\ Firouzeh Dehghan ${ }^{3}$ \\ Maizatulakmal Yahayu ${ }^{4}$ \\ Gwendoline Cheng Lian Ee ${ }^{5}$ \\ Mun Fai Loke ${ }^{6}$ \\ Jamuna Vadivelu ${ }^{6}$ \\ 'Department of Pharmacy, Faculty of \\ Medicine, University of Malaya, Kuala \\ Lumpur, Malaysia; ${ }^{2}$ Medical Research \\ Center, Jazan University, Jazan, Saudi \\ Arabia; ${ }^{3}$ Department of Exercise \\ Science, Sports Centre, University of \\ Malaya, Kuala Lumpur, ${ }^{4}$ Department of \\ Bioproduct Research and Innovation, \\ Institute of Bioproduct Development \\ (IBD), Universiti Teknologi Malaysia \\ (UTM), Johor Bahru, ${ }^{5}$ Department \\ of Chemistry, Faculty of Science, \\ Universiti Putra Malaysia (UPM), \\ Serdang, ${ }^{6}$ Department of Medical \\ Microbiology, Faculty of Medicine, \\ University of Malaya, Kuala Lumpur, \\ Malaysia
}

Purpose: $\beta$-Mangostin (BM) from Cratoxylum arborescens demonstrated various pharmacological activities such as anticancer and anti-inflammatory. In this study, we aimed to investigate its antiulcer activity against ethanol ulcer model in rats.

Materials and methods: BM was isolated from C. arborescens. Gastric acid output, ulcer index, gross evaluation, mucus production, histological evaluation using hematoxylin and eosin and periodic acid-Schiff staining and immunohistochemical localization for heat shock protein 70 (HSP70) and Bax proteins were investigated. Possible involvement of reduced glutathione, lipid peroxidation, prostaglandin E2, antioxidant enzymes, superoxide dismutase and catalase enzymes, radical scavenging, nonprotein sulfhydryl compounds, and anti-Helicobacter pylori were investigated.

Results: BM showed antisecretory activity against the pylorus ligature model. The pretreatment with BM protect gastric mucosa from ethanol damaging effect as seen by the improved gross and histological appearance. BM significantly reduced the ulcer area formation, the submucosal edema, and the leukocytes infiltration compared to the ulcer control. The compound showed intense periodic acid-Schiff staining to the gastric mucus layer and marked amount of alcian blue binding to free gastric mucus. BM significantly increased the gastric homogenate content of prostaglandin E2 glutathione, superoxide dismutase, catalase, and nonprotein sulfhydryl compounds. The compound inhibited the lipid peroxidation revealed by the reduced gastric content of malondialdehyde. Moreover, BM upregulate HSP70 expression and downregulate Bax expression. Furthermore, the compound showed interesting anti-H. pylori activity.

Conclusion: Thus, it could be concluded that BM possesses gastroprotective activity, which could be attributed to the antisecretory, mucus production, antioxidant, HSP70, antiapoptotic, and anti-H. pylori mechanisms.

Keywords: gastric ulcer, reactive oxygen species, heat shock protein 70

\section{Introduction}

Peptic ulcer disease is the most prevalent disorder of the gastrointestinal tract that hinders a lot of people worldwide. Many internal and external aggressive factors are thought to be involved in the pathogenesis and progression of the disease. ${ }^{1}$ In general, a peptic ulcer occurs when the offensive factors overcome the defensive ones. ${ }^{2}$ There are various noxious agents that attack the stomach, which in turn result in mucosal ulceration, such as Helicobacter pylori infection, excessive ingestion of nonsteroidal anti-inflammatory drugs, alcohol beverage, psychological stress, and cigarette smoking. On the other hand, the stomach protects itself through many defense mechanisms, mainly in the entire mucosal layer, which acts as a barrier against inflammatory and
Correspondence: Heyam Mohamed Ali Sidahmed

Department of Pharmacy, Faculty of Medicine, University of Malaya, Jalan Universiti, 50603 Kuala Lumpur, Wilayah Persekutuan, Kuala Lumpur, Malaysia Tel +60 33666648 I

Email diamondhm@hotmail.com 
cytotoxic agents. ${ }^{3}$ Although there are many pharmacological antiulcer drugs, the therapeutic regimen for peptic ulcer treatment is considered to be one of the biggest clinical issues due to the less effectiveness and associated drawbacks of the reciprocal antiulcer drugs in the market, which limit their usage. Therefore, there is a trend to discover new antiulcer agent from medicinal flora with high efficacy and less or no toxicity. ${ }^{4}$ For centuries, people have been using a lot of herbs and different plants in the treatment of gastric ulcer in their traditional medicine. ${ }^{5}$ Indeed, medicinal plants offer a vast chemical structural diversity. In this regard, xanthones are chemical compounds that are highly distributed in the natural flora. In addition, they possess a variety of biochemical, biological, and pharmacological actions; $\alpha$-mangostin, $\beta$-mangostin (BM), and $\gamma$-mangostin are such examples. ${ }^{6}$

Cratoxylum arborescens (Guttiferae) is derived from the Latin word "arbor", which means tree, and it is widely distributed in Sabah and Sarawak. The bark, roots, and leaves of this plant are traditionally used for the treatment of diverse ailments such as fever, cough, diarrhea, itchiness, ulcer, chicken pox, and abdominal complaints. Our previous phytochemical investigation on C. arborescens have led to the isolation and identification of oxygenated and prenylated xanthones $\alpha$-mangostin, which demonstrated interesting gastroprotective activity. ${ }^{7}$ This is an important reason to investigate more bioactive compounds from this valuable plant. Among the ambiguous xanthones, BM compound have recently acquired great consideration due to its wide range of pharmacological activities, including anticancer, antibacterial, antifungal, antiviral, anti-inflammatory, and antimalarial activities. ${ }^{6}$ However, to the best of our knowledge, no study has been conducted on its antiulcer activity. Therefore, in our ongoing search for bioactive antiulcer compounds from Malaysian flora, BM was successfully extracted and isolated from $C$. arborescens. The potential compound was subjected to several experimental tests to evaluate its antiulcerogenic property and to identify the possible gastroprotective mechanism against ethanol ulcer models in experimental rats.

\section{Materials and methods Drugs and chemicals}

The drugs and reagents were prepared immediately before use. The following substances were used: omeprazole, alcian blue, 5,5'-dithiobis-(2-nitrobenzoic acid) (DTNB), phosphate-buffered saline, mammalian protease inhibitor cocktail, trichloroacetic acid, thiobarbituric acid, butylated hydroxytoluene, tetramethoxypropane, 2,4,6-Tri(2-pyridyl)-striazine, ferrous sulfate, ferric chloride hexahydrate, sucrose, sodium acetate buffer, magnesium chloride, diethyl ether,
Tris-buffered saline, and dimethyl sulfoxide (DMSO) (all from Sigma-Aldrich, St Louis, MO, USA); absolute ethanol and hydrochloric acid (all from Merek KGaA, Darmstadt, Germany); and ketamil and xylazil (all from Pet Arcade Co., Kuala Lumpur, Malaysia). All chemical substances and reagents used in this study were of analytical grade.

\section{Plant materials}

The stem bark of $C$. arborescens was collected from the wild trees growing in Sarawak in 2009. A voucher specimen has been deposited at the Herbarium, Department of Biology, Universiti Putra Malaysia, Serdang, Malaysia.

\section{Extraction and isolation of BM from C. arborescens}

The ground air-dried stem bark of $C$. arborescens $(1.0 \mathrm{~kg})$ was soaked at room temperature in hexane for consecutive 3 days and repeated thrice. The extract was filtered and then concentrated by utilizing a rotary evaporator under reduced pressure to obtain a dark gummy semisolid residue. The resulting product was then serially extracted with chloroform and methanol. The weights of hexane, chloroform, and methanol crude extracts gained were $6.12,28.18$, and $40.27 \mathrm{~g}$, respectively. The hexane extract $(6.12 \mathrm{~g})$ was separated by vacuum column chromatography and eluted with hexane and followed by mixtures of solvents, hexane/chloroform, chloroform/ethyl acetate, and ethyl acetate/methanol to give 26 fractions of $200 \mathrm{~mL}$ each. Similar fractions based on thin layer chromatography and observed under ultraviolet light were combined. Fraction 14 was further separated by minicolumn chromatography to give 56 fractions. Fractions 16-52 (eluted with 50\% ethyl acetate:50\% methanol) was likewise further purified by preparative thin layer chromatography and chromatotron to yield a yellowish solid that was defined as BM. The same method of separation and fractionation was followed for the chloroform and methanol extracts with series of column chromatography that result in the isolation of an additional batch of BM.

BM was initially obtained as yellowish solid and yellowish needle-shaped crystals after being recrystallized with hot chloroform. IR $v_{\text {max }} \mathrm{cm}^{-1} 1(\mathrm{KBr}): 3,407(\mathrm{OH}), 2,923$ $(\mathrm{CH}), 1,642(\mathrm{C}=\mathrm{O})$, and 1,596 $(\mathrm{C}=\mathrm{C})$; ultraviolet $\mathrm{MeOH} \lambda_{\text {max }}$ $\mathrm{nm}(\log \varepsilon): 374$ (1.89), 350 (3.99), 344 (2.19), and 340 (3.29); electron ionized mass spectrometry $\mathrm{m} / \mathrm{z}$ (\% intensity): 424 (53.79), 409 (5.20), 393 (1.19), 3.81 (19.45), 368 (31.93), 353 (100.00), 335 (20.79), 310 (7.59), 299 (23.66), and 169 (8.41); proton nuclear magnetic resonance (500 MHz, acetone- $\left.d_{6}\right): \delta 13.61(\mathrm{OH}-1), 9.62(\mathrm{OH}-6), 6.82(s, 1 \mathrm{H}, \mathrm{H}-5)$, $6.47(s, 1 \mathrm{H}, \mathrm{H}-4), 5.25(t, J=6.9 \mathrm{~Hz}, 1 \mathrm{H}, \mathrm{H}-12), 5.18(t, J=6.9$ $\mathrm{Hz}, 1 \mathrm{H}, \mathrm{H}-17), 4.10$ ( $d, J=6.9 \mathrm{~Hz}, 2 \mathrm{H}, \mathrm{H}-11), 3.94$ (OMe-3), 
3.77 (OMe-7), 3.29 (d, J=6.9 Hz, 2H, H-16), $1.80(s, 3 \mathrm{H}$, Me-14), 1.75 ( $s, 3 \mathrm{H}, \mathrm{Me}-19), 1.63$ ( $s, 3 \mathrm{H}, \mathrm{Me}-15)$, and 1.61 $(s, 3 \mathrm{H}, \mathrm{Me}-20)$; carbon-13 nuclear magnetic resonance $(125$ $\mathrm{MHz}$, acetone- $\left.d_{6}\right): \delta 186.8(\mathrm{C}-9), 168.5(\mathrm{C}-4 \mathrm{a}), 164.4(\mathrm{C}-1)$, 161.5 (C-10a), 160.2 (C-6), 160.1 (C-3), 148.5 (C-7), 142.0 (C-8), 135.4 (C-18 and C-13), 128.6 (C-12), 127.2 (C-17), 115.9 (C-8a), 115.7 (C-2), 108.0 (C-9a), 106.6 (C-5), 93.8 (C-4), 65.2 (OMe-7), 60.4 (OMe-3), 30.8 (C-11), 29.8 (C-15), 29.8 (C-20), 25.8 (C-16), 22.2 (C-14), and 21.7 (C-19).

The chemical structure of BM (Figure 1A) was recognized based on the distinctive correlations in heteronuclear multiple bond connectivity, heteronuclear multiple quantum coherence, distortionless enhancement by polarization transfer along with the signals shown by $1 \mathrm{H}$ and carbon- 13 nuclear magnetic resonance spectra. The fragmentation pattern and molecular mass of BM were further established through the electron impact mass spectrometry and the typical absorption bands of the functional groups were displayed from the infrared spectroscopic data. The high-performance liquid chromatography result showed that the purity of BM was $>99 \%$ (Figure 1B). The purity, physical characteristics, and the structure of BM elucidated in this study was in accordance with literature standards previously documented to obtain from C. arborescens. ${ }^{8}$

\section{Animals}

Disease-free mix sexes of male and female Sprague Dawley rats $(200-250 \pm 5 \mathrm{~g})$ and their standard commercial feed pellets were purchased from the Experimental Animal Unit,
University of Malaya, Faculty of Medicine, Institutional Animal Care and Use Committee (FOM IACUC), Kuala Lumpur, Malaysia. All animals reserved under the same and the steady atmospheric circumstances for the temperature of $22^{\circ} \mathrm{C}$, with 12 hours light/dark cycles and free access to feed and distilled water. Rats were caged in groups of two to three each and left for 1 week as acclimatization period. The animal study in this work was submitted to the ethical reviewer committee (Faculty of Medicine-Institutional Animal Care \& Use Committee) for authorization (ethics No 2013-10-8/FAR/R/ HMAS), and ethics was granted (2013-10-8/FAR/R/HMAS) ${ }^{9}$ All in vivo experimental procedures were performed in sterile condition in FOM IACUC, following their guidelines.

\section{Pylorus ligature ulcer model}

The effect of the study compounds on gastric acid output was evaluated in Shay ulcer model following the recommended method. ${ }^{9,10}$ Sprague Dawley rats were appointed evenly into five groups $(n=6)$. After overnight fasting, the animals were anesthetized using ketamine $50 \mathrm{mg} / \mathrm{kg}$ and xylazine $5 \mathrm{mg} / \mathrm{kg}$, then their abdomen was open, and the pylorus was ligated. Straight away following the pylorus ligature; animals received the treatments intraduodenally $(5 \mathrm{~mL} / \mathrm{kg}$ body weight [bw]) according to the following grouping: Group-1 control (5\% Tween $80 \mathrm{v} / \mathrm{v}$ ); Group-2 standard (omeprazole 20 mg/kg); Group-3 BM (5 mg/kg); Group-4 BM (10 mg/kg); and Group-5 BM (20 mg/kg).

Following treatment, the abdomen was then sutured. After 4 hours, the rats were victimized by $\mathrm{CO}_{2}$ chamber,
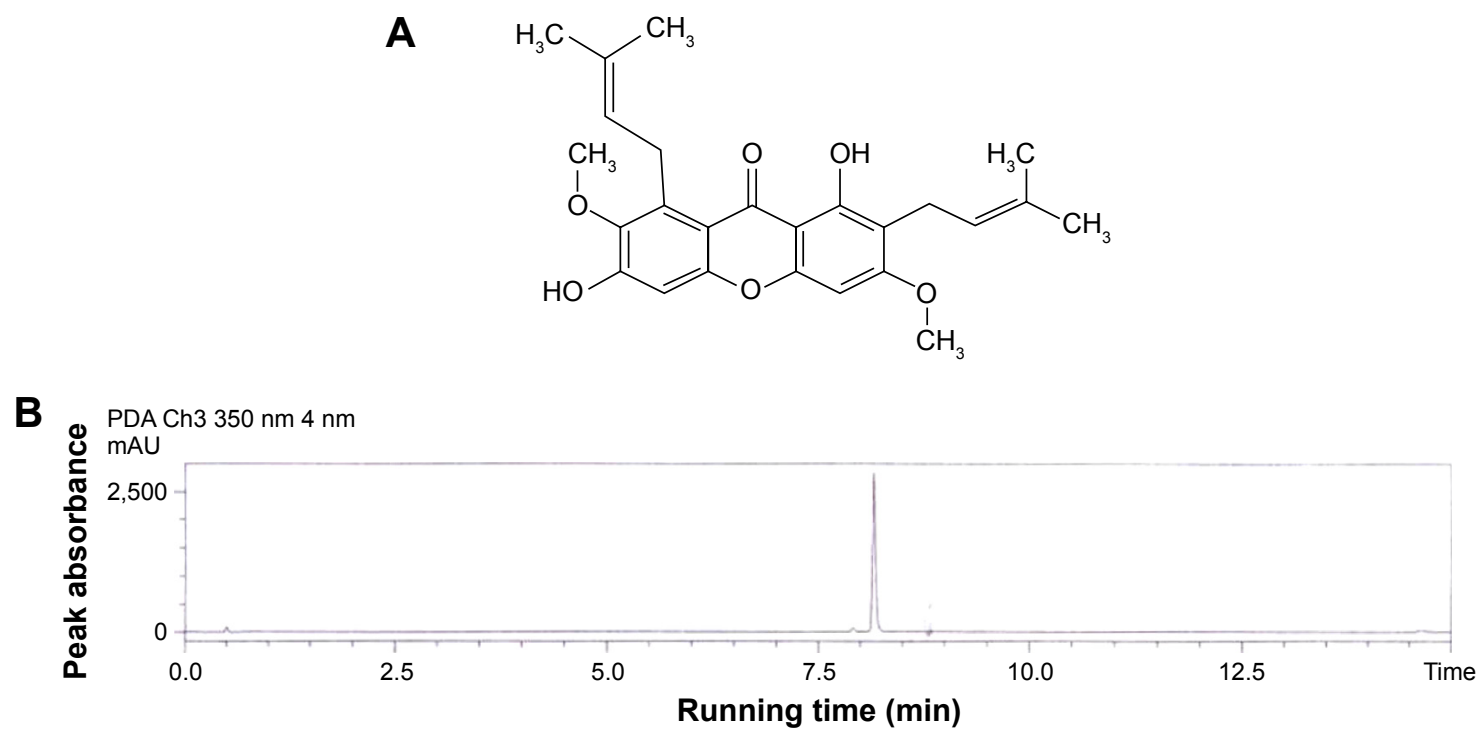

Figure I Chemical structure and purity of BM.

Notes: (A) Represents the chemical structure of BM. (B) Shows the separation of BM by HPLC following the solid phase extraction method (chromatogram of standard $\mathrm{BM}[10 \mu \mathrm{g} / \mathrm{mL}])$.

Abbreviations: BM, $\beta$-mangostin; HPLC, high-performance liquid chromatography; min, minutes; PDA, photodiode array; mAU, milli absorption unit. 
the abdomen was incised to put ligature in the lower part of the esophagus, then instantly the stomachs were taken away and the gastric juice was poured into tubes and centrifuged at $2,000 \times g$ for 5 minutes and the gastric secretion volume (mL) was determined. ${ }^{11}$ The $\mathrm{pH}$ value of the gastric juice was recorded using a digital $\mathrm{pH}$ meter. The total acidity of the gastric juice was measured through titrating with 0.01 $\mathrm{N}$ sodium hydroxide and phenolphthalein as indicator. One milliliter of the gastric juice was transferred into $100 \mathrm{~mL}$ conical flask, phenolphthalein solution was dropped and the reaction was preceded pending a distinct pink color appeared. The whole volume of alkali used in the titration was recorded. The total acidity (expressed as $\mathrm{mEq} / \mathrm{L}$ ) was determined by the following formula:

$$
\begin{aligned}
\text { Acidity }= & (\text { Volume of } \mathrm{NaOH} \times \text { Normality of } \mathrm{NaOH} \\
& \times 100 / 0.1) \times \mathrm{mEq} / \mathrm{L} / 100 \mathrm{~g}
\end{aligned}
$$

\section{Ethanol ulcer model}

Sprague Dawley rats were divided randomly into six groups $(\mathrm{n}=6)$. Overnight fasted animals were treated orally $(5 \mathrm{~mL} / \mathrm{kg}$ bw) as follows: Group-1 normal control (5\% Tween $80 \mathrm{v} / \mathrm{v})$; Group-2 ulcer control (5\% Tween $80 \mathrm{v} / \mathrm{v})$; Group-3 standard (omeprazole 20 mg/kg); Group-4 BM (5 mg/kg); Group-5 BM (10 mg/kg); and Group-6 BM (20 mg/kg).

After 1 hour, all groups except group-1 received absolute ethanol $(5 \mathrm{~mL} / \mathrm{kg})^{2}$. One hour later, blood was obtained for serum biochemical analysis via cardiac puncture under anesthetic condition using ketamine $50 \mathrm{mg} / \mathrm{kg}$ and xylazine $5 \mathrm{mg} / \mathrm{kg}$, then the rats were euthanized by $\mathrm{CO}_{2}$ chamber. The abdomen were incised and the stomachs were immediately removed. Each stomach was open along the greater curvature, washed by ice-cold normal saline, photographed, and subjected for the evaluation of apparent mucosal damage, mucus content, histological evaluation, and for further mechanistic studies.

\section{Calculation of gastroprotection inhibition percentage}

Gastroprotection inhibition percentage was measured following the procedure described by Sidahmed et al. ${ }^{7}$ The gastric ulcers appeared as elongated bands of hemorrhagic lesions. The length $(\mathrm{mm})$ and the width $(\mathrm{mm})$ of each band were measured using a planimeter $\left(\left[10 \times 10 \mathrm{~mm}^{2}=\right.\right.$ ulcer area $\{\mathrm{UA}\}]$ under dissecting microscope $[\times 1.8])$. The area of each ulcer lesion was measured by counting the number of small squares, $2 \times 2 \mathrm{~mm}$, covering the length and width of each ulcer band. The sum of the areas of all lesions for each stomach was applied in the calculation of the UA wherein the sum of small squares $4 \times 1.8=\mathrm{UA}^{2} \mathrm{~m}^{2}$. The inhibition percentage
(I\%) was calculated by the following formula as described by Njar et al ${ }^{12}$ with slight modifications:

$$
\underset{\text { percentage }(\mathrm{I} \%)}{\text { Inhibition }}=\frac{\text { UA control }- \text { UA treated }}{\text { UA control }} \times 100 \%
$$

\section{Measurement of gastric mucus content}

Once the stomachs were opened, they were washed with icecold normal saline to keep the mucus layer on the mucosa surface. The gastric mucosa of each animal subjected to ethanol-induced gastric ulcer was gently rubbed off using a glass slide, and the weight of the collected mucus was measured using a precise electronic balance. ${ }^{13,14}$

\section{Serum biochemical analysis}

The collected blood samples were centrifuged for 10 minutes at $11,940 \times g$ to get pure serum, which was stored at $-80^{\circ} \mathrm{C}$ before use for serum biochemical analysis. Serum samples were analyzed at the University of Malaya Medical Centre using automated clinical chemistry analyzer (Hitachi 902auto- analyzer, Roche, Japan) to evaluate possible changes in serum biochemical parameters: liver function test, kidney function test, and lipid profile. ${ }^{15,16}$

\section{Histological evaluation with hematoxylin and eosin staining}

A small fragment of the gastric wall from each animal was fixed in $10 \%$ buffered formalin solution followed by tissue dehydrated with alcohol and xylene. Then, each sample was embedded in paraffin wax, sectioned at $5 \mu \mathrm{m}$ in slides prior to staining. Hematoxylin and eosin (H\&E) stain was used for light microscopy for general histological evaluation. ${ }^{17}$

\section{Lesion scoring system}

Histopathological analysis was made using a light microscope with an inverted digital camera (Olympus BX60, Olympus Optical Co., Ltd., Tokyo, Japan) and the evaluation was performed by a pathologist who was unaware and blinded to the treatments. The results were graded according to the literatured scoring system. ${ }^{18}$ The microscopic scoring was as follows: epithelial cell loss (score: 0-3), edema in submucosa (score: $0-4)$, hemorrhagic damage (score: $0-4)$, and the presence of inflammatory cells (score: $0-3$ ). The maximum total score was estimated up to 14 .

\section{Periodic acid-Schiff staining}

In order to localize the gastric mucus production, some slides were stained by periodic acid-Schiff (PAS) base following the manufacturer instruction (Sigma-Aldrich, periodic acid-Schiff kit). 


\section{Determination of gastric biochemical parameters}

Preparation of gastric tissue homogenate

According to the prescribed method of Sidahmed et al, ${ }^{9}$ immediately after scarification, glandular gastric tissue was washed thoroughly with ice-cold saline. Using a homogenizer (Polytron, Heidolph RZR 1, Schwabach, Germany), small fragment of each stomach was homogenized $(10 \% \mathrm{w} / \mathrm{v})$ in ice-cold phosphate-buffered saline $(0.1 \mathrm{M} / \mathrm{L})$ containing mammalian protease inhibitor cocktail. The homogenates were then centrifuged at $10,000 \times g$ for 15 minutes at $4^{\circ} \mathrm{C}$. The pure supernatant was aliquoted and stored at $-80^{\circ} \mathrm{C}$ prior for quantifying biochemical parameters in gastric tissue homogenate as described below.

\section{Estimation of alcian blue-bound gastric mucus}

According to the recommended method of Bandyopadhyay et al, ${ }^{19}$ small segment of gastric tissue was first weighed, then immersed for 2 hours in $10 \mathrm{~mL}$ alcian blue solution $(0.1 \% \mathrm{w} / \mathrm{v}$ alcian blue $+0.16 \mathrm{M}$ sucrose $+50 \mathrm{mM}$ sodium acetate buffer at a $5.6 \mathrm{pH}$ ). A total of $0.25 \mathrm{M}$ sucrose was used to wash the tissues for 15 and 45 minutes interval. Further, $10 \mathrm{~mL}$ of $0.5 \mathrm{mM}$ magnesium chloride was added to isolate the mucus and shaken intermittently each for 30 minutes intervals for 2 hours, followed by the addition of an equal volume of diethyl ether to the extract, and shaking vigorously for 2 minutes. The resulting suspended solution was centrifuged at $3,000 \times g$ for 10 minutes. ${ }^{20}$ The diethyl ether layer discharged, and the absorption of the bound alcian blue in the aqueous layer was read in spectrophotometry at $580 \mathrm{~nm}$. The results were recorded as microgram alcian blue/gram tissue weight.

\section{Estimation of prostaglandin E2}

According to Poonam et al, ${ }^{21}$ the gastric mucosal production of prostaglandin $\mathrm{E} 2\left(\mathrm{PGE}_{2}\right)$ was estimated using enzyme immunoassay kit for prostaglandin (PG) evaluation (Cayman Chemicals, Ann Arbor, MI, USA). The test was carried out by mixing the standards or sample homogenate, enzymatic tracer, and specific antiserum in equal volume of $50 \mu \mathrm{L}$. The mixture was allowed to react for 1 hour, followed by incubation with $200 \mu \mathrm{L}$ Ellman's reagent for further 1 hour. The absorbance was measured spectrophotometrically at $412 \mathrm{~nm}$. The results displayed as ng of $\mathrm{PGE}_{2} / \mathrm{mg}$ of protein.

\section{Reduced glutathione levels}

Total glutathione (GSH) content was estimated by interaction with DTNB, and the absorbance read on a spectrophotometer $(412 \mathrm{~nm})$. The results were expressed in $\mathrm{nM} \mathrm{GSH} / \mathrm{g}$ tissue. ${ }^{22}$

\section{Thiobarbituric acid reactive substance assay}

According to Hodges et $\mathrm{al}^{23}$ the gastric mucosal homogenate was mixed with freshly prepared thiobarbituric acid reactive substance solution ( $26 \mathrm{mM}$ thiobarbituric acid, $0.26 \mathrm{M} \mathrm{HCl}$, $15 \%$ trichloroacetic acid, and $0.02 \%$ butylated hydroxytoluene). The mixture was allowed to react in a water bath at $95^{\circ} \mathrm{C}$ for 1 hour, followed by centrifugation at 3,500 $\mathrm{g}$ for 15 minutes. The absorbance was recorded using a spectrophotometer at $532 \mathrm{~nm}$. The results were displayed as $\mu \mathrm{M} / \mathrm{g}$ tissue malondialdehyde (MDA). Tetramethoxypropane used as a reference.

\section{Superoxide dismutase activity analysis}

Measurements were performed according to superoxide dismutase (SOD) Cayman manufacturer's instructions. The measurement mixture is approximately $230 \mu \mathrm{L}$ and consists of the following solutions: $200 \mu \mathrm{L}$ tetrazolium salt solution $+10 \mu \mathrm{L}$ supernatant $+20 \mu \mathrm{L}$ xanthine oxidase $(167 \mathrm{U} / \mathrm{L})$. The mixture was allowed to incubate for 20 minutes. The absorbance of the purple-colored formazan was measured at $560 \mathrm{~nm}$. The results were expressed as SOD unit/mg protein, where SOD unit is the expression of that amount of enzyme required to show $50 \%$ dismutaion of the $\mathrm{O}_{2}^{-\cdot}$ radical. ${ }^{24}$

\section{Catalase activity analysis}

Measurements were performed according to catalase (CAT) Cayman manufacturer's instructions. The measurement mixture contains $100 \mu \mathrm{L} 100 \mathrm{mM}$ potassium phosphate assay buffer $+30 \mu \mathrm{L}$ methanol $+20 \mu \mathrm{L} \mathrm{H}_{2} \mathrm{O}_{2}+20 \mu \mathrm{L}$ supernatant. The mixture was allowed to incubate for 20 minutes followed by the addition of $30 \mu \mathrm{L} \mathrm{KOH}$ and $30 \mu \mathrm{L}$ purpald. Ten minutes later, $10 \mu \mathrm{L}$ of $\mathrm{KIO}_{4}$ was added. After 5 minutes, the absorption of the purple color formed was measured at $540 \mathrm{~nm}$. The results were expressed as $\mathrm{nM} \mathrm{H}_{2} \mathrm{O}_{2} / \mathrm{min} / \mathrm{mg}$ protein.

\section{Ferric reducing antioxidant power assay}

The FRAP (ferric reducing antioxidant power) value of BM was estimated according to the recommended method of Benzie and Strain. ${ }^{25}$ Briefly, $50 \mu \mathrm{L}$ of BM/buffer was mixed with $1.5 \mathrm{~mL}$ of freshly prepared FRAP reagent (10 mM 2,4,6-Tri(2-pyridyl)-striazine solution in $40 \mathrm{mM} \mathrm{HCl}$ and $20 \mathrm{mM} \mathrm{FeCl}_{3} \cdot 6 \mathrm{H}_{2} \mathrm{O}$ solution in proportions of 10:1:1 (v/v), respectively). The mixture was allowed to react in the dark at room temperature for 5 minutes. The absorbance was then measured at $593 \mathrm{~nm}$ and plot against $\mathrm{FeSO}_{4}$ as standard, and the results were displayed as $\mu \mathrm{M} \mathrm{Fe}$ (II)/g dry weight of the compound.

\section{Estimation of nonprotein sulfhydryls content}

Gastric mucosal nonprotein sulfhydryls content (NP-SH; $\mu \mathrm{M} / \mathrm{g}$ of tissue) was measured according to the method of 
Sedlak and Lindsay. ${ }^{26}$ Briefly, $5 \mathrm{~mL}$ of gastric homogenate was added to a volume of $5 \mathrm{~mL} 50 \%$ trichloroacetic acid solution. Then the mixture was vortexed and centrifuged at $4,000 \times g$ for 10 minutes. A total of $2 \mathrm{~mL}$ was taken from the pure supernatant and mixed with $4 \mathrm{~mL}$ of $0.4 \mathrm{M}$ Trisbuffered saline, $\mathrm{pH}$ 8.9. A total of $0.1 \mathrm{~mL}$ of DTNB was added to the mixture to start the reaction. The absorbance was measured using a spectrophotometer at $412 \mathrm{~nm}$ for not more than 5 minutes of DTNB addition.

\section{Immunohistochemistry}

For further mechanistic study, tissue slides underwent for immunohistochemistry staining using Dako ARK ${ }^{\mathrm{TM}}$ (DAKO Corporation, Carpinteria, CA, USA) to observe immunohistochemical localization of heat shock protein 70 (HSP70) (1:100) (to evaluate the effect over oxidative stress), Bax (1:100) (proapoptotic marker to evaluate the effect over apoptosis). The proteins were purchased from Santa Cruz Biotechnology, Inc., Dallas, TX, USA.

\section{Anti-H. pylori activity}

The microtiter broth dilution method was used to define the minimum inhibitory concentration (MIC) of BM against H. pylori. According to Sidahmed et al, ${ }^{9}$ two $H$. pylori strains, national collection of type cultures 11637 (American type culture collection 43504) and J99 (ATCC 700824) were isolated from a human gastric biopsy sample. The pathogens were incubated in special condition in culture media containing brain heart infusion broth and $10 \%$ horse serum equipped with $\mathrm{CO}_{2}$ at $37^{\circ} \mathrm{C}$ for 72 hours. In brief, BM was mixed with $5 \%$ DMSO to prepare a $10 \times$ solution. $H$. pylori was mixed with the culture media to make up a stock solution of $2 \times 10^{6} \mathrm{CFU} / \mathrm{mL}$. Using sterilized 96-well polypropylene microtiter plates, $10 \mu \mathrm{L}$ of $\mathrm{BM}$ was mixed with $90 \mu \mathrm{L}$ of $H$. pylori in the wells, in order to prepare graded concentration that ranged from 31.25 to $250 \mathrm{mg}$. Wells containing $10 \mu \mathrm{L}$ of $H$. pylori with 5\% DMSO was utilized as control, and well containing $250 \mu \mathrm{g} / \mathrm{mL}$ of BM in brain heart infusion broth medium was served as blank. The microtiter plate was allowed to incubate for 72 hours equipped with $\mathrm{CO}_{2}$ at $37^{\circ} \mathrm{C}$. The plate was evaluated via microplate reader at $600 \mathrm{~nm}$ to find out the minimum concentration of the compound that prohibited the growth of $H$. pylori completely. The results were displayed as MIC. On the other hand, the minimum bactericidal concentration was studied in a chocolate agar plate equipped with 7\% lysed horse blood. The findings were displayed following the guidelines of the Clinical and Laboratory Standards Institute. ${ }^{27}$

\section{Statistical analysis}

All tests were done at least in triplicates, unless stated otherwise, and the resulted values were displayed as mean \pm SEM (standard error of the mean). The significant statistical differences between groups were calculated with the aid of SPSS 16.0 software (SPSS, Chigaco IL, USA) using ordinary one-way analysis of variance followed by Dunnett's multiple comparison tests. Analysis and graphs were prepared with GraphPad Prism version 5.02 for Windows, GraphPad Software, San Diego, CA, USA (www.graphpad.com). A value of $P<0.05$ was considered significant and denoted by (*).

\section{Results \\ Effect of BM on gastric acid secretion}

Intraduodenal administration of BM at doses of 5, 10, and $20 \mathrm{mg} / \mathrm{kg}$ bw and omeprazole at $20 \mathrm{mg} / \mathrm{kg}$ to the rats immediately after pylorus ligature significantly $(P<0.05)$ reduced the acid output of the gastric content secreted during a period of 4 hours. Table 1 shows the statistical significant differences between treatment groups on gastric acid secretion compared to the control.

\section{Gastroprotective effect of BM against ethanol gastric ulcer model} Gross evaluation in ethanol ulcer model

Macroscopic observation (Figure 2) showed that pretreated groups with 5,10 , and $20 \mathrm{mg} / \mathrm{kg}$ of BM (Figure 2D, E, and F, respectively) and omeprazole (Figure 2C) considerably reduced gastric lesion compared to the ulcer control group. The ulcer control showed intense gastric mucosal damage in the form of an elongated band of hemorrhages due to ethanol administration (Figure 2B). Table 2 shows that the pretreatment with $\mathrm{BM}$ at the study doses has significantly $(P<0.05)$ reduced the UA formation compared to the ulcer control.

Table I Effects of BM administered intraduodenally on the biochemical parameters of gastric juice obtained from pylorus ligature in rats

\begin{tabular}{llll}
\hline Treatment & $\begin{array}{l}\text { Volume } \\
(\mathbf{m L})\end{array}$ & $\mathbf{p H}$ & $\begin{array}{l}\text { Total acidity } \\
(\mathbf{m E q} / \mathrm{L})\end{array}$ \\
\hline $\begin{array}{l}\text { Ulcer control } \\
(5 \% \text { Tween } 80 \mathrm{v} / \mathrm{v})\end{array}$ & $6.233 \pm 0.30$ & $2.617 \pm 0.22$ & $203.3 \pm 6.1$ \\
Omeprazole $(20 \mathrm{mg} / \mathrm{kg})$ & $1.867 \pm 0.15^{*}$ & $4.617 \pm 0.32^{*}$ & $70.00 \pm 4.65^{*}$ \\
BM $(5 \mathrm{mg} / \mathrm{kg})$ & $1.883 \pm 0.12^{*}$ & $3.527 \pm 0.16^{*}$ & $93.33 \pm 7.92^{*}$ \\
BM $(10 \mathrm{mg} / \mathrm{kg})$ & $2.000 \pm 0.12^{*}$ & $3.795 \pm 0.11^{*}$ & $92.50 \pm 8.24^{*}$ \\
BM $(20 \mathrm{mg} / \mathrm{kg})$ & $2.367 \pm 0.12^{*}$ & $4.528 \pm 0.17^{*}$ & $128.3 \pm 9.09^{*}$ \\
\hline
\end{tabular}

Notes: Results are mean \pm SEM $(n=6)$. Statistical comparison was performed using ANOVA followed by Dunnett's test. $* P<0.05$ when compared to control group.

Abbreviations: ANOVA, analysis of variance; BM, $\beta$-mangostin; SEM, standard error of the mean. 

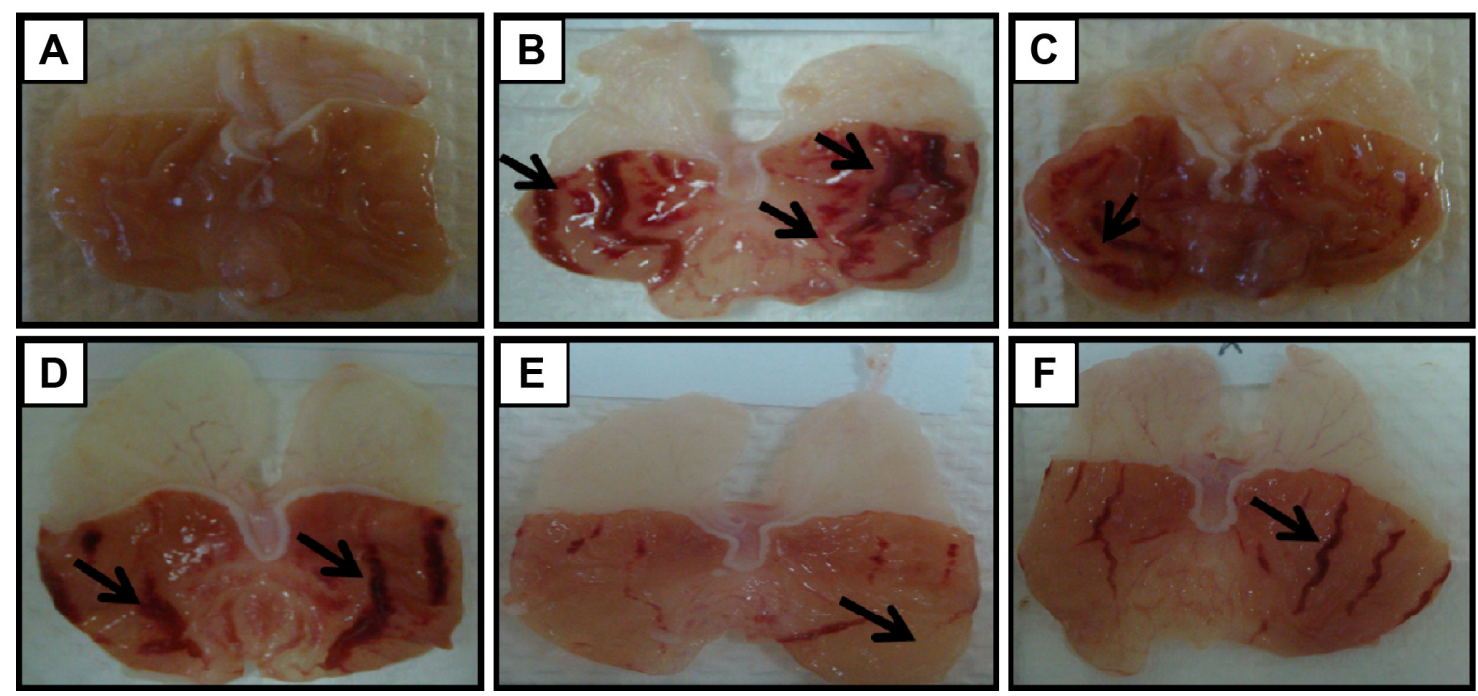

Figure 2 Macroscopic evaluation.

Notes: The macroscopic appearance of the gastric mucosa of the rats of the normal control (A) exhibit the intact mucosal appearance with no lesions as seen. Whereas, the rats of the ulcer control pretreated with only Tween 80 (B) showed that the ethanol-induced severe visible lesions to the gastric mucosa appeared as elongated bands of hemorrhage (black arrows). However, the pretreatment with omeprazole at $20 \mathrm{mg} / \mathrm{kg}$ (C) showed mild lesions as seen in the gastric mucosa (black arrow). The pretreatment with BM at $5 \mathrm{mg} / \mathrm{kg}$ (D) showed moderate lesions as seen in the gastric mucosa (black arrows). The pretreatment with BM at $10 \mathrm{mg} / \mathrm{kg}$ (E) showed very mild lesions as seen in the gastric mucosa (black arrow). The pretreatment with BM at $20 \mathrm{mg} / \mathrm{kg}(\mathbf{F})$ showed mild lesions as seen in the gastric mucosa (black arrow) (magnification: $\times 1.8)$. Abbreviation: BM, $\beta$-mangostin.

\section{Gastric mucus content in ethanol ulcer model}

The results showed that the rats of the ulcer group had decreased amount of mucus content than that of the normal control, which might be attributed to the intragastric administration of ethanol. However, the pretreatment with BM at 5,10 , and $20 \mathrm{mg} / \mathrm{kg}$ bw and omeprazole at $20 \mathrm{mg} / \mathrm{kg}$ has increased the gastric mucus content compared to the ulcer control group.

\section{Effect of BM on serum biochemical test in ethanol ulcer model}

The serum biochemical analysis of the blood samples collected from animals pretreated with $\mathrm{BM}$ at different treatment doses against ethanol ulcer model is shown in

Table 2 Observed ulcer area and inhibition percentage of BM against ethanol-induced gastric ulcer in rats

\begin{tabular}{llll}
\hline Pretreatment & $\begin{array}{l}\text { Dose } \\
(\mathbf{m g} / \mathbf{k g})\end{array}$ & $\begin{array}{l}\text { Ulcer area } \\
\left(\mathbf{m m}^{2}\right)\end{array}$ & $\begin{array}{l}\text { Inhibition } \\
(\%)\end{array}$ \\
\hline Ethanol ulcer control & - & $557.3 \pm 9.588$ & - \\
Normal control (vehicle) & - & - & 100 \\
Omeprazole & 20 & $115.2 \pm 11.00^{*}$ & 79.07 \\
BM & 5 & $236.2 \pm 49.93^{*}$ & 57.62 \\
BM & 10 & $89.28 \pm 50.15^{*}$ & 83.98 \\
BM & 20 & $148.3 \pm 31.47^{*}$ & 73.39 \\
\hline
\end{tabular}

Notes: Data are expressed as mean $\pm \operatorname{SEM}(n=6), * P<0.05$; significant vs ulcer control. Statistical analysis was performed using one-way ANOVA followed by Dunnett's test for multiple comparisons.

Abbreviations: ANOVA, analysis of variance; BM, $\beta$-mangostin; SEM, standard error of the mean.
Table 3. The results showed that the group of rats pretreated with only Tween 80 and induced to develop gastric ulcer by ethanol administration had increased level of liver enzymes aspartate aminotransferase, alanine aminotransferase, and reduced level of albumin and electrolyte findings compared to the normal control, making a significant disturbance in the liver enzymes test, lipid profile as well as in the renal function test. However, the pretreatment with $\mathrm{BM}$ at doses of 5,10 , and $20 \mathrm{mg} / \mathrm{kg}$ bw and omeprazole at $20 \mathrm{mg} / \mathrm{kg}$ has normalized the serum profile compared to the ulcer control group.

\section{H\&E staining in ethanol ulcer model}

Histological observation (Figure 3A) showed normal histological observation of the intact stomach without any lesion. Ethanol-induced gastric lesion in ulcer control group pretreated with only Tween 80 showed highly extensive gastric lesion, submucosal and leukocytes infiltration (Figure 3B), while pretreated groups by omeprazole at $20 \mathrm{mg} / \mathrm{kg}$ (Figure $3 \mathrm{C}$ ) or BM at 5,10 , and $20 \mathrm{mg} / \mathrm{kg}$ (Figure 3D-F, respectively) have shown relatively better histological appearance and protection from ethanol damaging effect as seen by decreasing mucosal damage, reduction or complete absence of edema, and leukocytes infiltration. The histological appearance of the stained gastric mucosa by $H \& E$ stain was interpreted as lesion score for each group in Table 4. 
Table 3 Serum biochemical analysis of animal pretreated by BM against ethanol-induced gastric ulcer

\begin{tabular}{|c|c|c|c|c|c|c|}
\hline \multirow[t]{2}{*}{ Parameter } & \multirow{2}{*}{$\begin{array}{l}\text { Normal } \\
\text { control }\end{array}$} & \multirow{2}{*}{$\begin{array}{l}\text { Ulcer } \\
\text { control }\end{array}$} & \multicolumn{4}{|c|}{ Dose administered (mg/kg bw) } \\
\hline & & & OMP 20 & BM 5 & BM 10 & BM 20 \\
\hline AP (IU/L) & $60.4 \pm 1.44$ & $95.7 \pm 1.02$ & $69.67 \pm 2 *$ & $80.80 \pm 9.3^{*}$ & $76.80 \pm 8.5^{*}$ & $90.4 \pm 8.3^{*}$ \\
\hline ALT (IU/L) & $30.4 \pm 0.5 \mathrm{I}$ & $66.0 \pm 1.14$ & $38.2 \pm 2.5^{*}$ & $51.8 \pm 1.62 *$ & $51.0 \pm 17.3^{*}$ & $48.0 \pm 5.62^{*}$ \\
\hline AST (IU/L) & $152.0 \pm 3.0$ & $192.0 \pm 2.0$ & $100.8 \pm 4 *$ & $106.8 \pm 5.3^{*}$ & $108.4 \pm 3.5^{*}$ & $183.8 \pm 9.6^{*}$ \\
\hline Sodium (mmol/L) & $139.1 \pm 0.1$ & $137.3 \pm 1.79$ & $137.8 \pm 1.9$ & $|43.8 \pm 0 .|^{*}$ & $\mid 39.0 \pm 1.1 *$ & $138.8 \pm 0.4^{*}$ \\
\hline Potassium (mmol/L) & $4.80 \pm 0.15$ & $3.42 \pm 0.12$ & $4.16 \pm 0.0 *$ & $4.44 \pm 0.04 *$ & $4.56 \pm 0.12 *$ & $4.58 \pm 0.08^{*}$ \\
\hline Chloride (mmol/L) & $102.8 \pm 0.2$ & $99.80 \pm 1.4$ & $101.0 \pm 1.7$ & $103.4 \pm 0.3^{*}$ & $100.8 \pm 1.2 *$ & $100.8 \pm 0.1^{*}$ \\
\hline Carbon dioxide (mmol/L) & $22.88 \pm 0.2$ & $20.98 \pm 1.2$ & $22.6 \pm 0.7^{*}$ & $21.96 \pm 0.5^{*}$ & $21.86 \pm 0.6^{*}$ & $21.24 \pm 0.4^{*}$ \\
\hline Anion gap (mmol/L) & $18.0 \pm 0.45$ & $21.5 \pm 0.97$ & $19.0 \pm 0.4 *$ & $20.0 \pm 0.96 *$ & $20.8 \pm 0.6 *$ & $20.6 \pm 0.41 *$ \\
\hline Urea (mmol/L) & $6.0 \pm 0.08$ & $7.7 \pm 0.56$ & $6.06 \pm 0.3^{*}$ & $6.58 \pm 0.59 *$ & $6.82 \pm 1.0^{*}$ & $6.62 \pm 0.6 I^{*}$ \\
\hline Creatinine (mmol/L) & $34.16 \pm 0.2$ & $49.67 \pm 0.2$ & $34.3 \pm 1.5^{*}$ & $37.2 \pm 4.3^{*}$ & $36.20 \pm 2.9 *$ & $36.40 \pm 2.5^{*}$ \\
\hline Total protein (g/L) & $66.3 \pm 0.2$ & $61.75 \pm 1.5$ & $64.0 \pm 0.7^{*}$ & $62.8 \pm 1.19 *$ & $63.8 \pm 1.83 *$ & $64.2 \pm 1.74 *$ \\
\hline Albumin $(g / L)$ & $39.60 \pm 0.4$ & $12.0 \pm 0.54$ & $36.33 \pm I^{*}$ & $29.6 \pm 0.4 I^{*}$ & $32.0 \pm 0.36 *$ & $34.4 \pm 0.4 I^{*}$ \\
\hline Globulin (g/L) & $25.20 \pm 0.2$ & $50.75 \pm 1.1$ & $35.6 \pm 0.4^{*}$ & $44.2 \pm 1.07^{*}$ & $35.8 \pm I .5 I^{*}$ & $37.8 \pm 1.75^{*}$ \\
\hline Triglyceride (mmol/L) & $0.36 \pm 0.0 \mathrm{I}$ & $0.45 \pm 0.08$ & $0.36 \pm 0.0 *$ & $0.40 \pm 0.08 *$ & $0.40 \pm 0.02 *$ & $0.46 \pm 0.04$ \\
\hline Total cholesterol (mmol/L) & $1.84 \pm 0.08$ & $1.40 \pm 0.10$ & $1.46 \pm 0.1 *$ & $1.42 \pm 0.12^{*}$ & $1.47 \pm 0.07^{*}$ & $1.42 \pm 0.14 *$ \\
\hline HDL cholesterol (mmol/L) & $1.29 \pm 0.07$ & $1.08 \pm 0.07$ & $1.17 \pm 0.1 *$ & $1.18 \pm 0.1 *$ & $1.09 \pm 0.17$ & $1.18 \pm 29.6 *$ \\
\hline
\end{tabular}

Notes: Data are expressed as mean \pm SEM $(n=6)$, $* P<0.05$; significant vs ulcer control. Statistical analysis was performed using one-way ANOVA followed by Dunnett's test for multiple comparison.

Abbreviations: ALT, alanine aminotransferase; ANOVA, analysis of variance; AP, alkaline phosphatase; AST, aspartate aminotransferase; BM, $\beta$-mangostin; HDL, highdensity lipoprotein; OMP, omeprazole; SEM, standard error of the mean; bw, body weight.
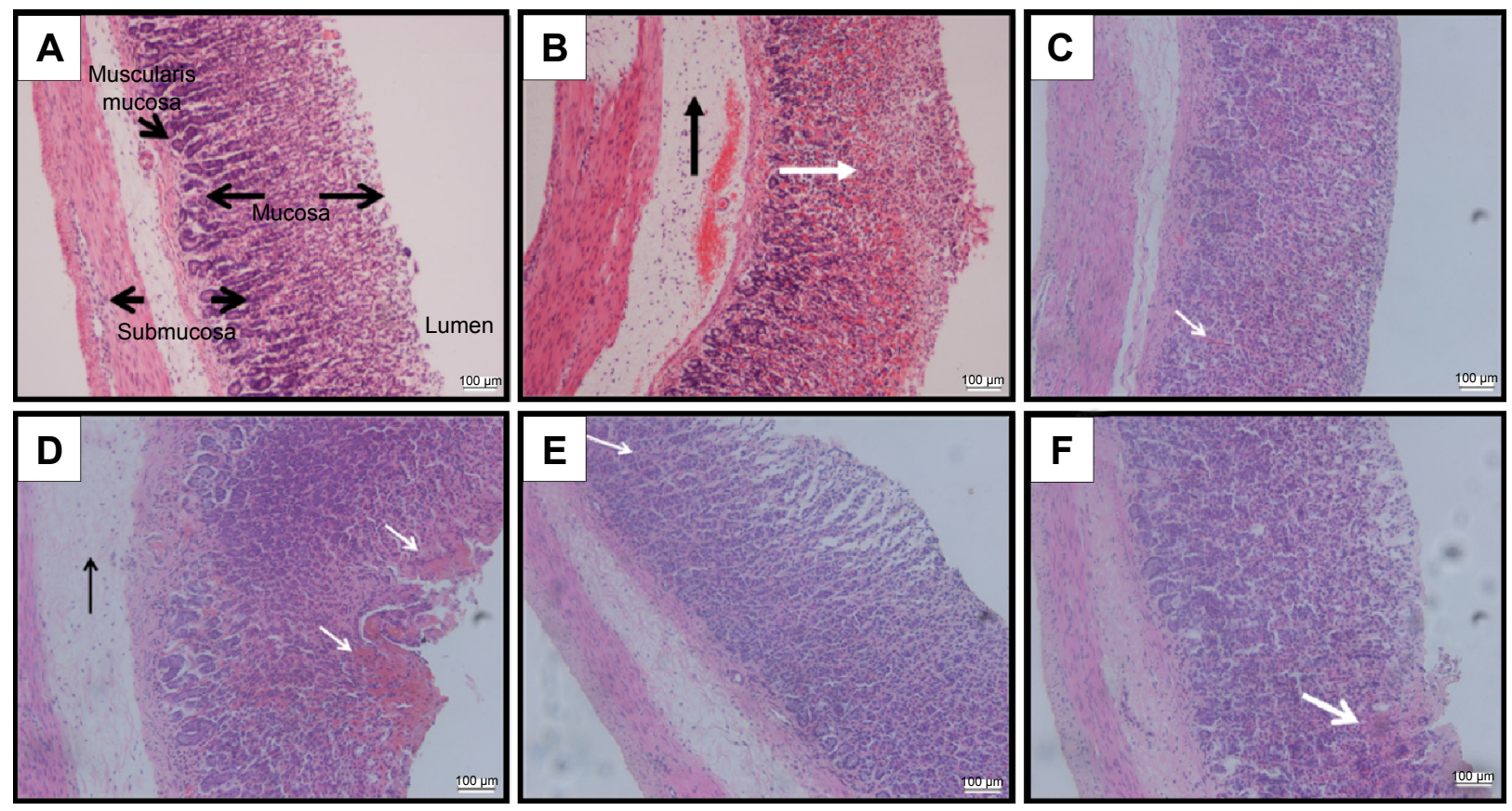

Figure 3 Histological evaluation.

Notes: The microscopic appearance of gastric mucosa of the rats of the normal control (A) showed normal histological arrangement of the gastric mucosa and submucosa with no tissue damage. The gastric mucosa of the rats of the ulcer control pretreated with only Tween 80 (B) showed that the ethanol-induced severe disruption to the surface epithelium and necrotic lesions penetrate deeply into mucosa (white arrow) and extensive edema of submucosal layer and leukocyte infiltration are present (black arrow). However, the pretreatment with omeprazole at $20 \mathrm{mg} / \mathrm{kg}$ (C) showed mild disruption of the surface epithelium mucosa and slight mucosal damage (white arrow) but no submucosal edema and leukocytes infiltration are seen. The pretreatment with BM at $5 \mathrm{mg} / \mathrm{kg}$ (D) showed moderate disruption of the surface epithelium mucosa and mucosal damage (white arrows) with submucosal edema and leukocytes infiltration as seen (black arrow). The pretreatment with BM at 10 mg/kg (E) showed very mild disruption of the surface epithelium mucosa and slight mucosal damage (white arrow) but no submucosal edema and leukocytes infiltration are seen. The pretreatment with $\mathrm{BM}$ at $20 \mathrm{mg} / \mathrm{kg}$ (F) showed mild disruption of the surface epithelium mucosa and slight mucosal damage (white arrow) but no submucosal edema and leukocytes infiltration are seen $(H \& E$ stain: $\times 20)$.

Abbreviations: BM, $\beta$-mangostin; H\&E, hematoxylin and eosin. 
Table 4 Lesion score of rat gastric tissue pretreated with BM against ethanol-induced gastric damage

\begin{tabular}{|c|c|c|c|c|c|}
\hline Pretreatment & $\begin{array}{l}\text { Hemorrhagic damage } \\
\text { (score 0-4) }\end{array}$ & $\begin{array}{l}\text { Submucosal edema } \\
\text { (score 0-4) }\end{array}$ & $\begin{array}{l}\text { Epithelial cell loss } \\
\text { (score 0-3) }\end{array}$ & $\begin{array}{l}\text { Inflammatory cells } \\
\text { (score 0-3) }\end{array}$ & $\begin{array}{l}\text { Total scoring } \\
\text { (scores 14) }\end{array}$ \\
\hline Normal control (vehicle) & 0 & 0 & 0 & 0 & 0 \\
\hline Ethanol ulcer control & $4(3-4)$ & $3(2-4)$ & $3(2-3)$ & I $(0-3)$ & II (4-I4) \\
\hline Omeprazole (20 mg/kg) & $0(0-2)^{*}$ & $2(1-2)^{*}$ & I $(0-2)^{*}$ & $0(0-1)^{*}$ & $4(2-5)^{*}$ \\
\hline $\mathrm{BM}(5 \mathrm{mg} / \mathrm{kg})$ & $3(2-4)$ & $3(I-4)$ & $2(I-3)$ & $\mid(0-1)^{*}$ & $9(2-10)$ \\
\hline $\mathrm{BM}(10 \mathrm{mg} / \mathrm{kg})$ & $0(0-2)^{*}$ & I $(0-2)^{*}$ & $0(0-1)^{*}$ & $0(0-1)^{*}$ & $2(0-4)^{*}$ \\
\hline BM (20 mg/kg) & $(I-3)^{*}$ & $2(1-3)^{*}$ & $I(I-2)^{*}$ & $\mid(0-1)^{*}$ & $5(2-8)^{*}$ \\
\hline
\end{tabular}

Notes: Data are expressed as mean \pm SEM $(n=6)$, $* P<0.05$; significant vs ulcer control. Statistical analysis was performed using one-way ANOVA followed by Dunnett's test for multiple comparisons.

Abbreviations: ANOVA, analysis of variance; BM, $\beta$-mangostin; SEM, standard error of the mean.

\section{PAS staining in ethanol ulcer model}

Since BM exhibits an increased gastric mucus content, PAS staining was used in this study to localize the presence of the glycoproteins, which appeared as magenta color. Figure 4A shows the normal gastric mucus production. The administration of absolute ethanol to the rats in the ulcer control group pretreated with only Tween 80 was led into a complete depletion of the mucus layer that lack this magenta color (Figure 4B). However, the rats pretreated by omeprazole at $20 \mathrm{mg} / \mathrm{kg}$ (Figure 4C), or BM resulted in the expansion of a substantial continuous PAS-positive mucus gel layer lining the entire gastric mucosal surface observed histologically as a bright-magenta-stained area lining the mucosa in contrast with the ulcer group. The positive PAS staining indicated the possible ability of BM to preserve the mucus layer against ethanol ulcer model.

\section{Alcian blue content in ethanol ulcer model}

The present study results showed that the pretreatment with $\mathrm{BM}$ at 5,10 , and $20 \mathrm{mg} / \mathrm{kg}$ bw and omeprazole at $20 \mathrm{mg} /$ $\mathrm{kg}$ has significantly $(P<0.05)$ increased alcian blue binding to free gastric mucus compared to the ulcer control group,
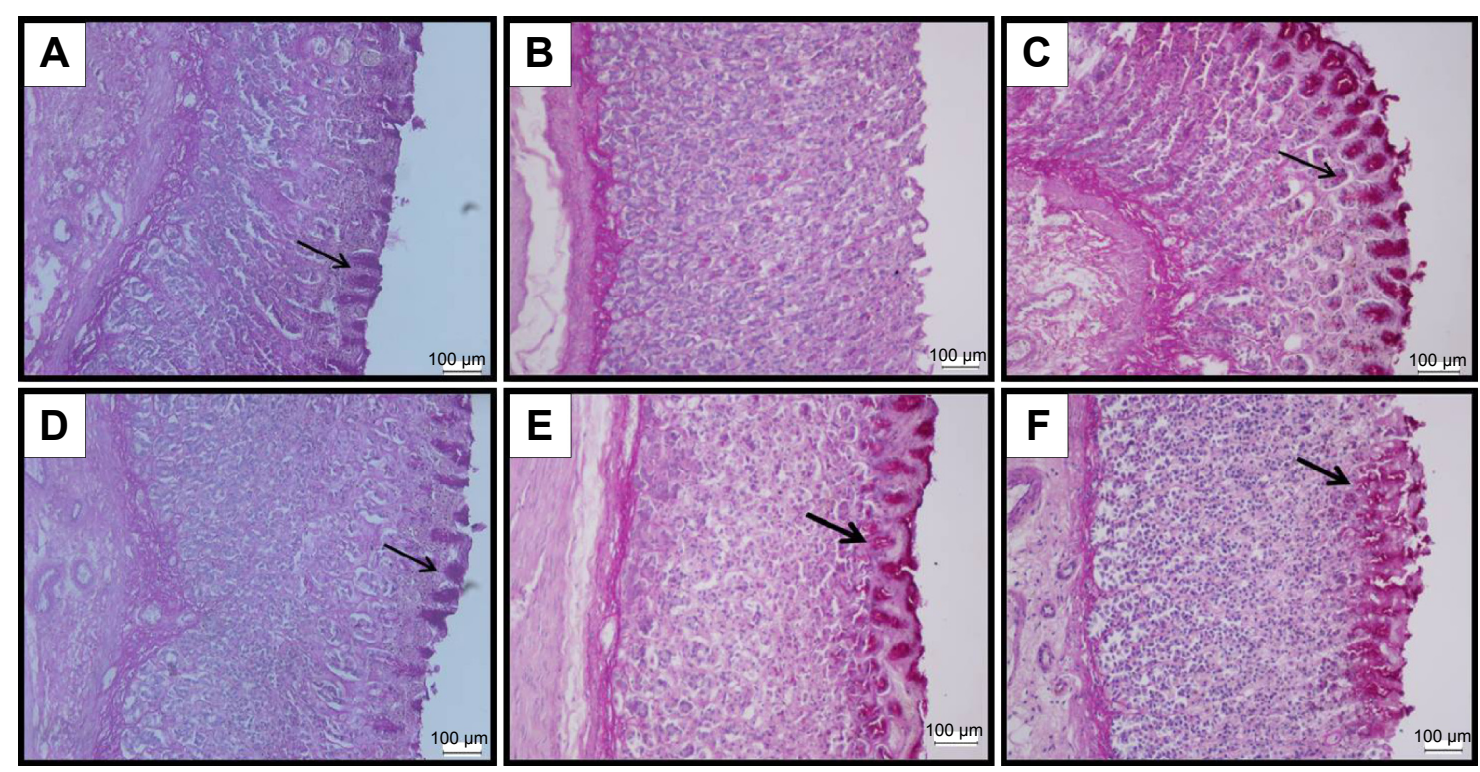

Figure 4 PAS staining.

Notes: The microscopic appearance of gastric mucosa of the rats of the normal control (A) showed the positive PAS stain noted as a bright-magenta color to the mucus cells lining the gastric pits (black arrow). The gastric mucosa of the rats of the ulcer control pretreated with only Tween 80 (B) showed that the ethanol-induced complete depletion to the mucous layer as seen by the absence of the PAS stain. However, the pretreatment with omeprazole at $20 \mathrm{mg} / \mathrm{kg}$ (C) showed intense PAS stain noted as a bright-magenta to the mucus cells lining the gastric pits due to the carbohydrate-rich, viscous mucus they secrete (black arrow). The pretreatment with BM at $5 \mathrm{mg} / \mathrm{kg}$ (D) showed moderate expansion of a substantial continuous PAS-positive mucous gel layer that lining the entire gastric mucosal surface observed histologically as a brightmagenta-stained area lining the mucosa (black arrow). The pretreatment with BM at $10 \mathrm{mg} / \mathrm{kg}$ (E) showed intense PAS stain and increased expansion of a substantial continuous PAS-positive mucous gel layer that lining the entire gastric mucosal surface observed histologically as a bright-magenta-stained area lining the mucosa (black arrow). The pretreatment with BM at $20 \mathrm{mg} / \mathrm{kg}(\mathbf{F})$ showed increased expansion of a substantial continuous PAS-positive mucous gel layer that lining the entire gastric mucosal surface observed histologically as a bright-magenta-stained area lining the mucosa (black arrow) (PAS stain: $\times 20)$.

Abbreviations: BM, $\beta$-mangostin; PAS, periodic acid-Schiff. 
A

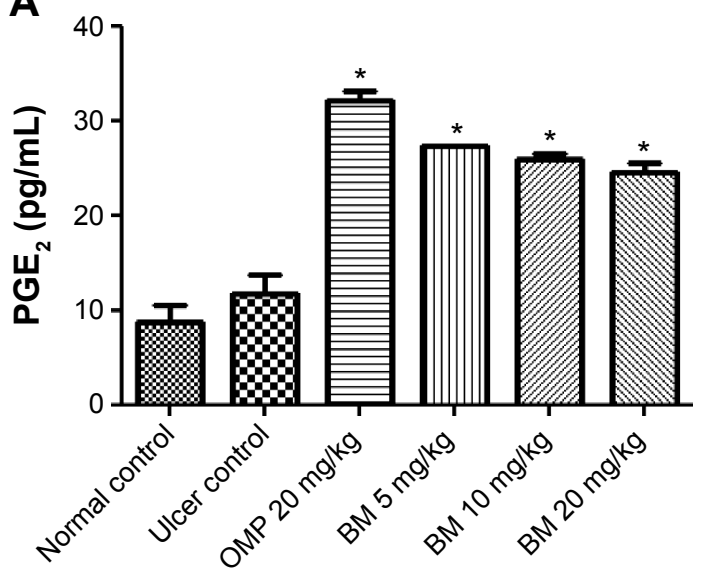

B

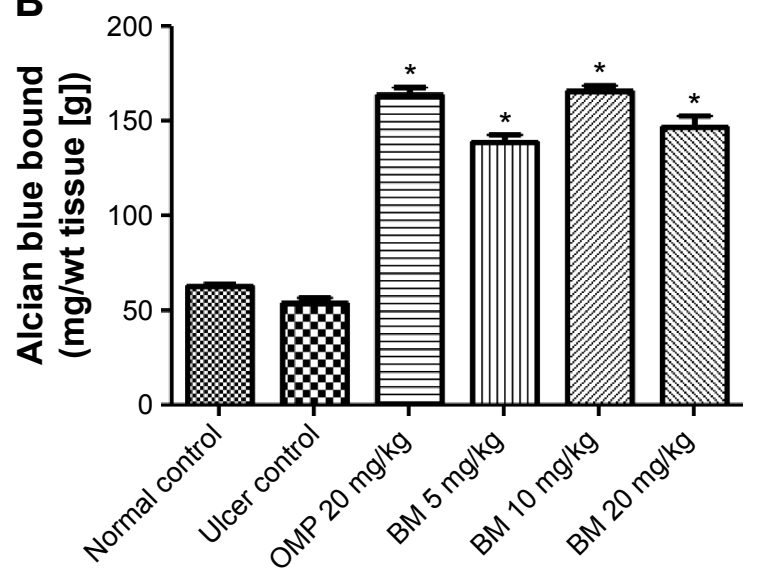

Figure 5 Effects of BM (BM; 5, 10, and $20 \mathrm{mg} / \mathrm{kg} \mathrm{bw}$ ) and omeprazole (OMP; $20 \mathrm{mg} / \mathrm{kg} \mathrm{bw}$ ) on (A) gastric mucosal PGE $\mathrm{E}_{2}$ levels and (B) alcian blue binding to free gastric mucus against ethanol-induced gastric ulcer in rat.

Notes: The rats of the ulcer control showed marked $(P<0.05)$ lower gastric mucosal levels of $\mathrm{PGE}_{2}$ and alcian blue binding to free gastric mucus. The gastric mucosal levels of $\mathrm{PGE}_{2}$ and alcian blue binding to free gastric mucus were significantly $(P<0.05)$ higher in the pretreated rats with $\mathrm{BM}$ than that of ulcer group. Each column represents data as mean \pm SEM $(n=6), * P<0.05$; significant vs ulcer control. Statistical analysis was performed using one-way ANOVA followed by Dunnett's test for multiple comparisons. Abbreviations: ANOVA, analysis of variance; BM, $\beta$-mangostin; OMP, omeprazole; PGE 2 , prostaglandin E2; SEM, standard error of the mean; bw, body weight.

indicating the positive effect of BM on surface mucus production against the depletion effect of ethanol (Figure 5A).

\section{Effect of BM on $\mathrm{PGE}_{2}$ level in ethanol ulcer model} In order to investigate the mechanistic effect of BM on mucus production, $\mathrm{PGE}_{2}$ level was estimated. The results showed that the pretreatment with $\mathrm{BM}$ at 5,10 , and $20 \mathrm{mg} / \mathrm{kg}$ bw and omeprazole at $20 \mathrm{mg} / \mathrm{kg}$ has significantly $(P<0.05)$ increased $\mathrm{PGE}_{2}$ level compared to the ulcer control group, where $\mathrm{PGE}_{2}$ level was low in the ulcer control group (Figure 5B).

\section{GSH gastric content}

GSH is an intracellular antioxidant compound; thus in this study, the determination of the gastric GSH level was used to evaluate the effect of BM over the antioxidant activity. The results, as shown in Figure 6A, showed that the ethanol administration to the rats in the ulcer control group pretreated with only Tween 80 has led to comparable reduction to the gastric GSH level than that of the normal control. However, the depleted GSH level was significantly $(P<0.05)$ restored in the pretreated animals with BM at 10 and $20 \mathrm{mg} / \mathrm{kg}$ bw and omeprazole at $20 \mathrm{mg} / \mathrm{kg}$ but not at the lower dose of BM $(5 \mathrm{mg} / \mathrm{kg})$. The results indicate the possible involvement of intracellular antioxidant activity mediated by BM against the oxidative damage induced by ethanol administration.

\section{Lipid peroxidation level}

MDA level was used as an indicator of lipid peroxidation and oxidative damage. Thus, in the current study, the concentration of the gastric MDA level was used to evaluate the effect of $\mathrm{BM}$ over the oxidative damage. The results as shown in Figure 6B showed that the concentration of MDA in the intact gastric mucosa was detected at a very low level, whereas MDA level was increased in the gastric tissue of the rats in the ulcer control group pretreated with only Tween 80 , which ascribed to the lipid peroxidation and oxidative damage due to ethanol administration. However, the elevated MDA level was significantly $(P<0.05)$ reduced in the pretreated animals with $\mathrm{BM}$ at 5,10 , and $20 \mathrm{mg} / \mathrm{kg}$ bw and omeprazole at 20 $\mathrm{mg} / \mathrm{kg}$ compared to the ulcer control group. The results might indicate the possible ability of BM to protect gastric mucosa from lipid peroxidation induced by ethanol administration.

\section{Antioxidant enzymes: SOD and CAT activity}

SOD and CAT are antioxidant enzymes, thus in the current study their activities were used to evaluate the antioxidant effect of BM against ethanol ulcer model. The results displayed that the SOD and CAT enzymes activities were reduced in the rats of the ulcer group compared to that of the normal group, which might be ascribed to the oxidative stress due to ethanol administration. However, pretreatment with BM at 10 and $20 \mathrm{mg} / \mathrm{kg}$ and omeprazole at $20 \mathrm{mg} / \mathrm{kg}$, but not with the lower dose of BM $(5 \mathrm{mg} / \mathrm{kg})$, has significantly increased $(P<0.05)$ the SOD activity (Figure 6C) and all the pretreatment groups showed significant increase $(P<0.05)$ of CAT activity (Figure 6D) in contrast with the ulcer control group. The present findings suggest the possible involvement of cellular antioxidant activity of BM in protecting the gastric mucosa against the damaging effect of ethanol in animal ulcer model. 


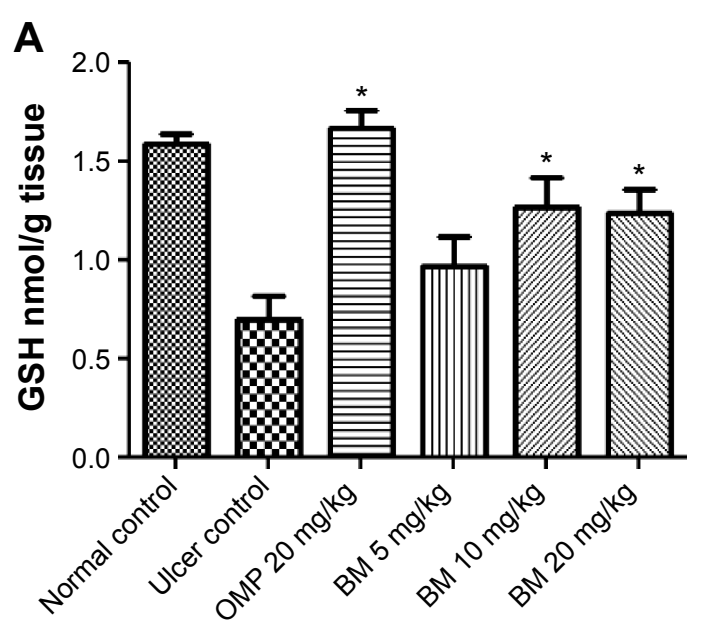

B
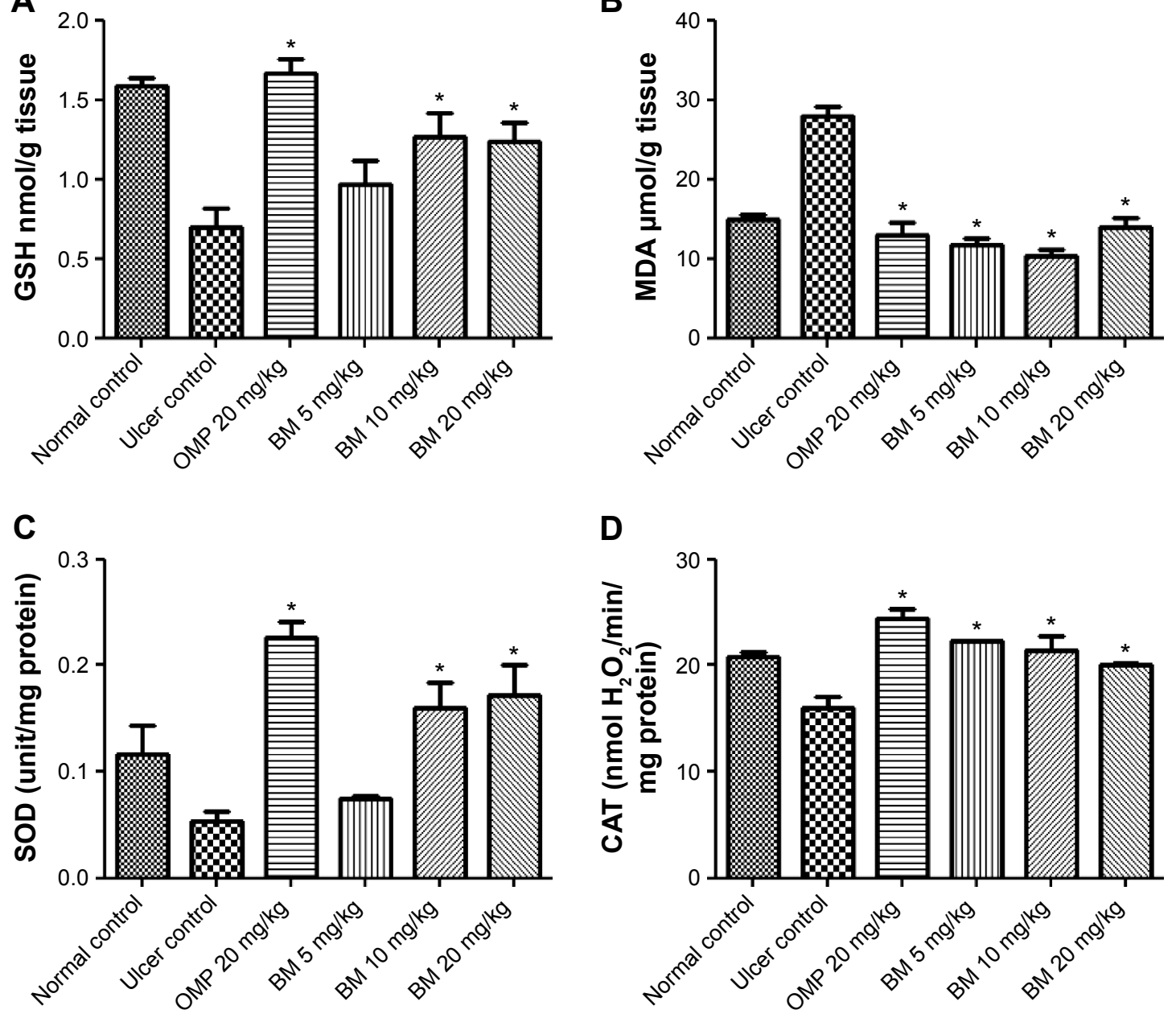

Figure 6 Effects of BM (5, 10, and $20 \mathrm{mg} / \mathrm{kg} \mathrm{bw})$ and OMP (20 mg/kg bw) on (A) GSH levels, (B) MDA level, (C) SOD activity, and (D) CAT activity against ethanol-induced gastric ulcer in rat.

Notes: The rats of the ulcer control showed marked $(P<0.05)$ lower gastric mucosal levels of GSH, CAT, and SOD, and significantly $(P<0.05)$ higher MDA. The gastric mucosal levels of GSH, CAT, and SOD were significantly $(P<0.05)$ higher in the pretreated rats with BM than that of ulcer group. The pretreated rats with BM were also expressed marked $(P<0.05)$ lower gastric mucosal levels of MDA than that of ulcer group. Each column represents data as mean $\pm S E M(n=6)$, $* P<0.05$; significant vs ulcer control. Statistical analysis was performed using one-way ANOVA followed by Dunnett's test for multiple comparisons.

Abbreviations: ANOVA, analysis of variance; BM, $\beta$-mangostin; CAT, catalase; GSH, glutathione; MDA, malondialdehyde; OMP, omeprazole; SEM, standard error of the mean; SOD, superoxide dismutase; bw, body weight.

\section{Antioxidant activity}

Since BM showed intracellular antioxidant activity, revealed by the improved gastric content of GSH, and the increased activities of SOD and CAT, the FRAPs assay was utilized to evaluate the antioxidant power of this natural compound. BM exhibited FRAP value of $131.5 \pm 12.85 \mu \mathrm{M} \mathrm{Fe}$ (II)/g dry mass, while the ascorbic acid used as a positive control in this study exhibited a value of $215.5 \pm 13.11 \mu \mathrm{M} F$ (II) $/ \mathrm{g}$ dry mass.

\section{NP-SH content}

Our observations as displayed in Figure 7 showed that the rats of the ulcer control pretreated with only Tween 80 had a comparable decreased level of NP-SH content of the gastric mucosa than that of the normal control group, which might be attributed to the absolute ethanol administration. However, the pretreatment with BM at 5,10 , and $20 \mathrm{mg} / \mathrm{kg}$ bw and omeprazole at $20 \mathrm{mg} / \mathrm{kg}$ bw has significantly $(P<0.05)$ preserved NP-SH content in gastric mucosa compared to the ulcer control group. These findings suggest the possible involvement of NP-SH in the gastroprotective effect of BM.

\section{Immunohistochemical results for potential gastroprotection antigens} HSP70 immunoreactivity in ethanol ulcer model

There was no detected immunoreactivity for HSP70 in the gastric tissue of the rats either in the normal control 


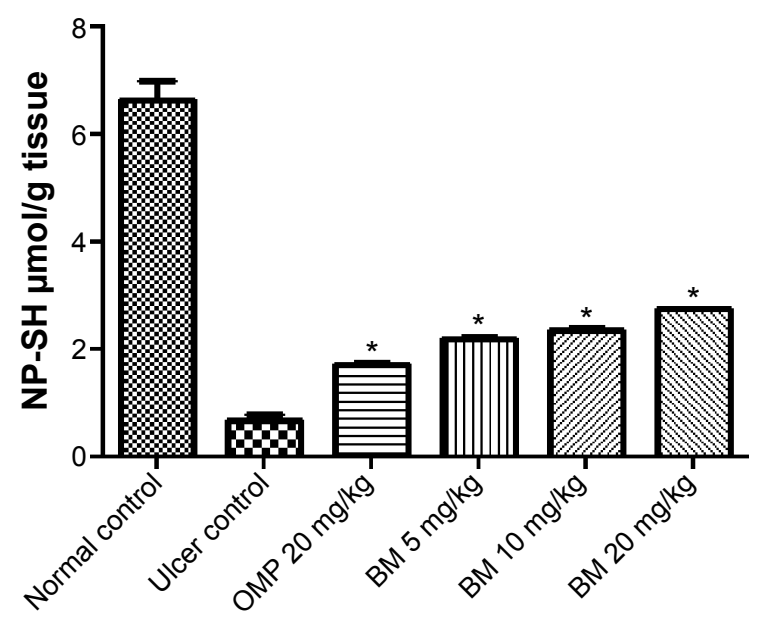

Figure 7 Effects of BM $(5,10$, and $20 \mathrm{mg} / \mathrm{kg} \mathrm{bw})$ and OMP $(20 \mathrm{mg} / \mathrm{kg}$ bw $)$ on gastric mucosal NP-SH content against ethanol-induced gastric ulcer in rat.

Notes: The rats of the ulcer control showed marked $(P<0.05)$ lower gastric mucosal levels of NP-SH. The gastric mucosal levels of NP-SH was significantly $(P<0.05)$ higher in the pretreated rats with BM than that of ulcer group. Each column represents data as mean $\pm \operatorname{SEM}(n=6), * P<0.05$; significant vs ulcer control. Statistical analysis was performed using one-way ANOVA followed by Dunnett's test for multiple comparisons. Abbreviations: ANOVA, analysis of variance; BM, $\beta$-mangostin; NP-SH, nonprotein sulfhydryls; OMP, omeprazole; SEM, standard error of the mean; bw, body weight.

(Figure 8A) or in the ulcer control (Figure 8B). However, immunohistochemical observation of HSP70 showed significant up-regulation of this protein in the pretreated animal with omeprazole at $20 \mathrm{mg} / \mathrm{kg}$ (Figure 8C) BM at 5, 10 and $20 \mathrm{mg} / \mathrm{kg}$ (Figure 8D-F, respectively) or omeprazole at $20 \mathrm{mg} / \mathrm{kg}$ (Figure $8 \mathrm{C}$ ) compared to the ulcer group. The concentration of the immune staining in the lesion area that appeared histologically as an intense brown color might indicate the possible ability BM to stimulate the adaptive cellular protection against ethanol ulcer model through the induction of HSP70.

\section{Bax immunoreactivity in ethanol ulcer model}

Bax is a proapoptotic protein, thus in this study Bax immunostaining was used to determine the effect of BM over apoptosis. The result showed that the rats in the normal control displayed significant Bax expression (Figure 9A). The ethanol ulcer group pretreated with only Tween 80 showed strong immunoreactivity for the Bax protein as appeared histologically as an intense brown color that was distributed throughout the damaged area in the gastric mucosa (Figure 9B). However, the pretreatment with omeprazole at $20 \mathrm{mg} / \mathrm{kg}$ (Figure 9C) or BM at 5,10 and $20 \mathrm{mg} / \mathrm{kg}$ (Figure 9D-F, respectively) or omeprazole at $20 \mathrm{mg} / \mathrm{kg}$ (Figure 9C) has comparably attenuated the ethanol-induced upregulation of Bax protein in the gastric mucosa. The results identified the suppressive effect of BM on Bax protein.

\section{In vitro anti-H. pylori activity}

Microtiter dilution method was used in the current study to determine the minimum concentration of this natural compound to prohibit the growth of $H$. pylori completely. BM
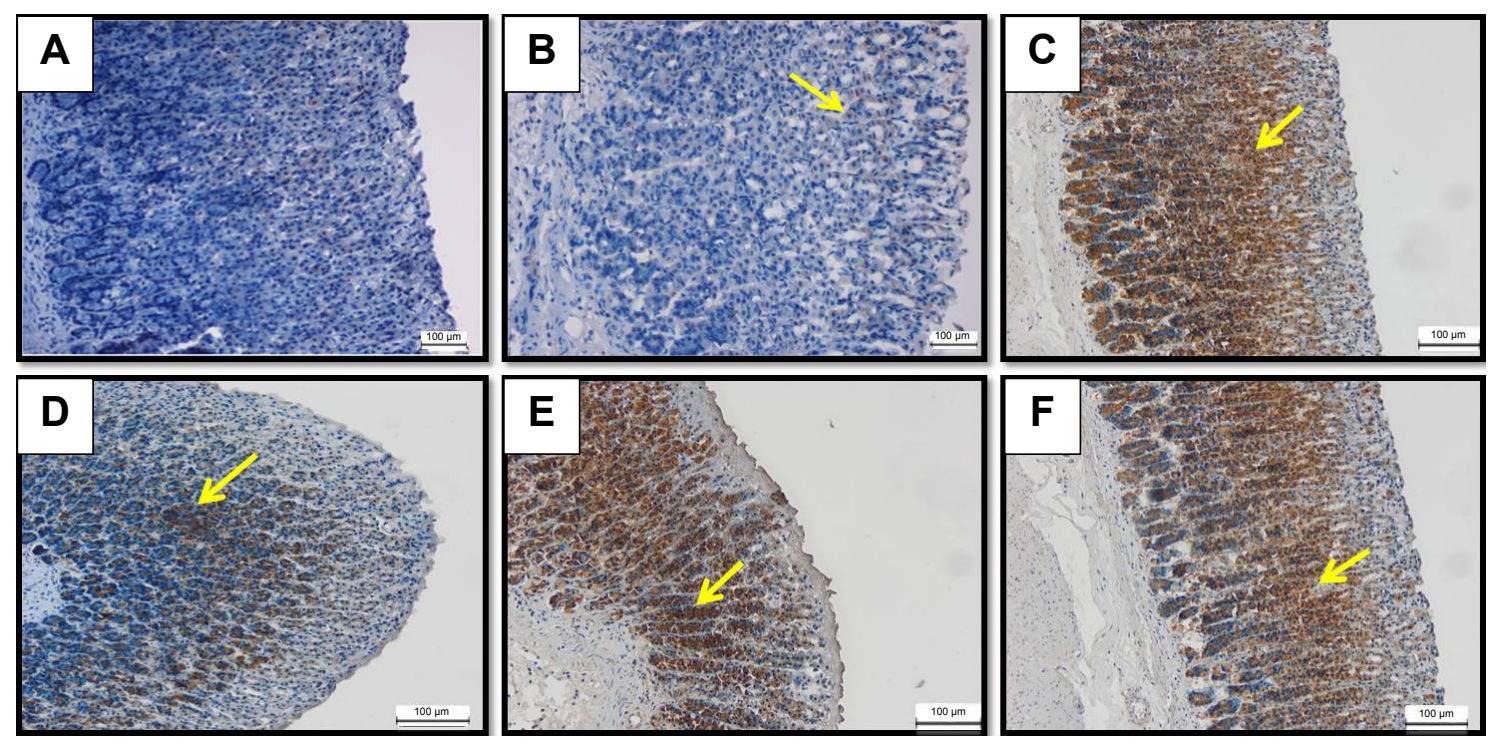

Figure 8 HSP70 IHC.

Notes: The microscopic appearance of gastric mucosa of the rats of the normal control (A) showed insignificant HSP70 expression in the normal gastric tissue. The gastric mucosa of the rats of the ulcer control pretreated with only Tween 80 (B) showed very mild HSP70 expression in the gastric tissue (yellow arrow). However, the pretreatment with omeprazole at $20 \mathrm{mg} / \mathrm{kg}$ (C) showed increased upregulation of HSP70 expression appeared histologically as an intense brown color to the positive-stained-antigen site in the gastric tissue (yellow arrow). The pretreatment with BM at $5 \mathrm{mg} / \mathrm{kg}$ (D) showed moderate upregulation of HSP70 expression appeared histologically as an intense brown color to the positive-stained-antigen site in the gastric tissue (yellow arrow). The pretreatment with BM at $10 \mathrm{mg} / \mathrm{kg}$ (E) showed highly increased upregulation of HSP70 expression appeared histologically as an intense brown color to the positive-stained-antigen site in the gastric tissue (yellow arrow). The pretreatment with BM at $20 \mathrm{mg} / \mathrm{kg}(\mathbf{F})$ showed increased upregulation of HSP70 expression appeared histologically as an intense brown color to the positive-stained-antigen site in the gastric tissue (yellow arrow) (IHC: $\times 20)$. Abbreviations: BM, $\beta$-mangostin; HSP70, heat shock protein 70; IHC, immunohistochemistry. 

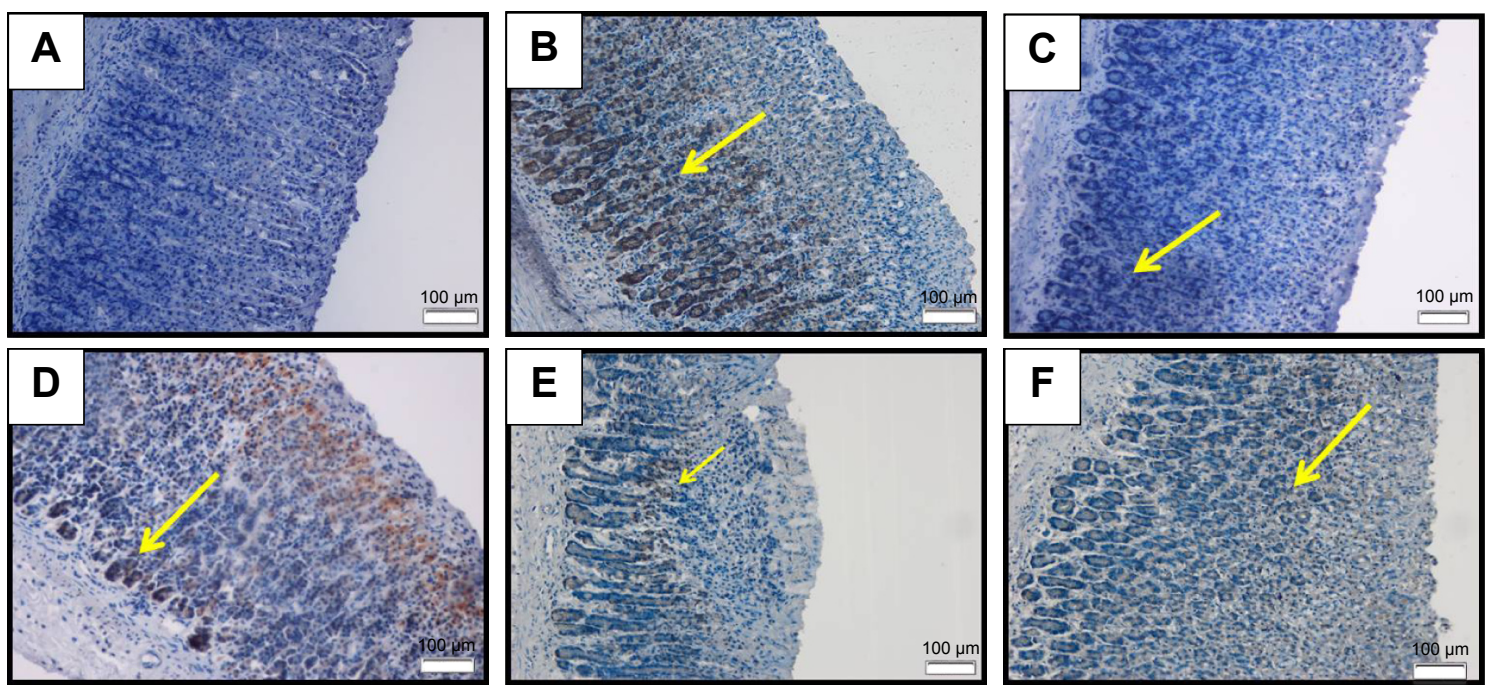

Figure $9 \mathrm{Bax} \mathrm{IHC}$.

Notes: The microscopic appearance of gastric mucosa of the rats of the normal control (A) showed insignificant Bax expression in the normal gastric tissue. The gastric mucosa of the rats of the ulcer control pretreated with only Tween 80 (B) showed highly increased Bax expression appeared histologically as an intense brown color to the positive-stained-antigen site in the gastric tissue (yellow arrow). The pretreatment with omeprazole at $20 \mathrm{mg} / \mathrm{kg}$ (C) showed very mild upregulation of Bax expression (yellow arrow). The pretreatment with BM at $5 \mathrm{mg} / \mathrm{kg}$ (D) showed moderate upregulation of Bax expression noted as brown color to the positive-stained-antigen site in the gastric tissue (yellow arrow). The pretreatment with BM at $10 \mathrm{mg} / \mathrm{kg}(\mathbf{E})$ showed very mild upregulation of Bax expression noted as brown color to the positive-stained-antigen site in the gastric tissue (yellow arrow). The pretreatment with BM at $20 \mathrm{mg} / \mathrm{kg}(\mathbf{F})$ showed mild upregulation of Bax expression noted as brown color to the positive-stainedantigen site in the gastric tissue (yellow arrow) $(\mathrm{IHC}: \times 20)$.

Abbreviations: BM, $\beta$-mangostin; IHC, immunohistochemistry.

demonstrated MIC values equal to $250 \mu \mathrm{g} / \mathrm{mL}$ and minimum bactericidal concentration $>250 \mu \mathrm{g} / \mathrm{mL}$.

\section{Discussion}

Gastric ulcer disease is one of the major gastrointestinal problem affecting many populations worldwide, with high morbidity and mortality rate. ${ }^{28}$ The pathogenesis of gastric ulcer has been studied for decades, and it has been found that the disease occurs when there is an imbalance between the gastric defensive factors and the aggressive factors. ${ }^{4}$ Many herbal medicines and their active ingredients have proved to be effective in treating and even preventing the recurrence of gastric ulcer disease, ${ }^{29}$ including one which is the topic of the current investigation. In this study, BM from C. arborescens demonstrated significant gastroprotective activity against ethanol-induced gastric ulcer in the animal model and the following discussion highlights its gastroprotective activity and the possible mechanisms involved.

Pylorus ligature is the most common animal model that is used to estimate the antisecretory effect of a tested compound by investigating its possible alteration on the gastric acid parameters. Many hypotheses have been suggested to identify the reason for the pylorus ligature to induce gastric hypersecretion. It may be related to the surgical intervention that causes the gastric enlargement, stimulating the vagovagal reflex, which in turn enhances gastric acid secretion. ${ }^{30}$ The gastric content collected from the pylorus-ligated rats pretreated with
$\mathrm{BM}$ was utilized to investigate the change in the $\mathrm{pH}$, volume, and the total acidity of gastric secretion. The results show that BM reduced the acid output of the gastric content. These results might augment the observed antiulcer activity of BM.

Ethanol is the most common gastric ulcer model that is frequently used due to its characteristics; the easy and rapid penetration properties into the gastric mucosa can cause numerous pathologic events, resulting in mucosal injuries. ${ }^{31}$ Ethanol administration immediately causes disturbance to the gastric endothelium that boosts membrane permeability and intracellular edema, which in turn results in the formation of severe hemorrhagic and necrotic lesions. ${ }^{32,33}$ The deleterious action of ethanol was found to be accomplished through several pathological changes, such as the depletion of the gastric mucus layer, reduction of bicarbonate secretion as well as diminished NP-SH content, ${ }^{34}$ in addition to the inhibition of PGs synthesis and the increase in reactive oxygen species (ROS) production..$^{35}$ In this study, BM exhibited an interesting gastroprotective activity against ethanol-induced gastric lesion at three different doses: 5,10 , and $20 \mathrm{mg} / \mathrm{kg}$ showed inhibition percentage by $57.62 \%, 83.98 \%$, and $73.39 \%$, respectively. The results show that the higher dose of BM ( 20 $\mathrm{mg} / \mathrm{kg}$ ) exerted less effectiveness compared to the medium dose $(10 \mathrm{mg} / \mathrm{kg})$ that exhibited the peak of the gastroprotective effect. This might be attributed to the high compatibility of the mechanisms underlying the gastroprotective effect of $\mathrm{BM}$ at $10 \mathrm{mg} / \mathrm{kg}$, but with less harmonization at $20 \mathrm{mg} / \mathrm{kg}$. 
In our effort to identify the possible side effects of BM on the overall clinical biochemical parameters, the liver function test, the kidney function test, and the lipid profile were evaluated. The results show that the rats in the ulcer group exhibited comparable disturbance to the lipid profile and the electrolyte findings. Moreover, the results also display an increased serum level of the liver enzymes (aspartate aminotransferase and alanine aminotransferase) as markers of hepatic injury, since an increased level of hepatic enzymes could be ascribed to alcoholic hepatitis due to ethanol administration. ${ }^{36}$ However, pretreatment with BM showed a significant decrease in such parameters near to that of the normal control level. The results could presumably be due to the high efficacy of this natural compound against ethanol-induced tissue damage.

Gastric mucus layer is thought to be the most important defensive gastric factor that acts as the first line to protect the gastric mucosa from bacterial infection as well as the diffusion of gastric acid and pepsin. ${ }^{37}$ In addition, gastric mucus possesses antioxidant properties. ${ }^{38}$ Ethanol is well known to extensively disturb the gastric mucus integrity. ${ }^{39}$ The positive impact of the antiulcer drugs on gastric mucus production in human samples has been reported earlier. Furthermore, many herbal drugs act to enhance mucosal protection by increasing mucus secretion..$^{40}$ This study found that BM preserved and enhanced the production of gastric-adherent mucus. This effect allows the viscous mucus layer to cover the gastric tissue against the deleterious effect of ethanol. PAS staining is the most common histological technique used to localize the presence of the glycogen. ${ }^{41}$ Therefore, PAS staining was conducted to determine the capability of BM to maintain the gastric mucus production. The results reveal the positive effect of BM in preserving the gastric mucus layer against the ethanol ulcer model. PGs are one of the most fundamental gastroprotective factors, mainly $\mathrm{PGE}_{2}$, since they function to maintain mucosal integrity by modulation of mucosal blood flow, inhibition of gastric acid secretion, and enhancement of mucus and bicarbonate production. ${ }^{28,42}$ Our current study showed that BM significantly preserved $\mathrm{PGE}_{2}$ level, which may explain the maintenance of gastric mucus layer following the pretreatment with BM.

The ROS are normal intracellular end products formed either subsequent to the ordinary cellular metabolic processes such as in mitochondria respiration or in the abnormal conditions such as inflammation. Primarily, they accumulate in the pathophysiological condition due to the imbalance between the production and the breakdown of ROS when the cellular antioxidant system could not control the ROS overproduction. ROS can interact with cellular components such as DNA, proteins, and lipids. Therefore, upon accumulation, ROS disrupt the normal physiologic cellular function, especially when they interact with the membrane proteins and enhance the lipid peroxidation that alter cell permeability, hence compromising all cellular functions. ${ }^{43}$ Superoxide anions and hydroxyl radicals are the most deleterious radicals. ${ }^{44}$ Gastrointestinal tissue has the ability to defend its cellular function against the damaging effect of accumulated ROS through its potent antioxidant elements that act as ROS scavenger including $\mathrm{CAT}$, SOD, and GSH. ${ }^{45}$ The SOD enzyme acts to shift the superoxide anion extracellularly by catalyzing the dismutation reaction of this radical into oxygen and $\mathrm{H}_{2} \mathrm{O}_{2} \cdot{ }^{46}$ The CAT enzyme functions to dissociate $\mathrm{H}_{2} \mathrm{O}_{2}$ into water and oxygen. ${ }^{47} \mathrm{GSH}$ is an essential nonenzymatic intracellular compound that defends against gastric ulcer progression due to its antioxidant properties, which offer cellular protection against oxidative stress. ${ }^{48} \mathrm{~A}$ previous study reported that the ethanol administration result in the diminished and inhibition of antioxidant enzymes activity, which brings about ROS accumulation that create a state of cellular oxidative stress. ${ }^{49}$ Additionally, ethanol administration induces an inflammatory condition to the gastrointestinal tissue as a sort of immune response, which liberates inflammatory cytokines and causes increased ROS production. In this situation, the cellular antioxidant system is not sufficient to overcome the accumulated ROS. Many studies have shown that the administration of extracellular antioxidant compound was found to be effective in preventing the deleterious effect of ethanol and its accompanied oxidative damage either directly or indirectly. ${ }^{50}$ Therefore, there is an urgent need to discover a potentially antioxidant compound with effective antiulcer properties for better mechanistic of drug action. In our current study, BM pretreatment exhibited interesting cellular antioxidant activity as it showed a significant increase in the gastric content of SOD, CAT, and GSH, which may indicate the possible incorporation of antioxidant mechanism in the observed gastroprotective effect of BM. Accumulated ROS react with cell membrane lipids, resulting in the formation of lipid peroxides that metabolize to generate MDA as the main end product of lipid peroxidation. Therefore, the MDA level is the direct practical index of oxidative tissue damage. ${ }^{51}$ Considering the role of ROS in gastric tissue damage, we evaluated the effect of BM in TBARS assay. The results show that BM significantly reduced the MDA level, which may augment the antioxidant activity of the compound and hence its gastroprotective action. 
Since BM enhanced the intracellular antioxidant system, it would be worthwhile to evaluate its antioxidant capacity. An antioxidant compound can be defined as the agent with the property to postpone or hinder the oxidative stress through radical scavenging activity and thus protect the tissue from oxidative damage..$^{52}$ Therefore, for further mechanistic study, the antioxidant activity of BM was examined through FRAP assay. A positive FRAP result means that the agent is an electron donor, which reduced the oxidized intermediate to a stable moiety and thus stopped the oxidation chain reaction. ${ }^{15}$ In the current study, the results of FRAP assay highlighted the positive antioxidant activity of BM.

NP-SH compounds are essential elements for mucosal cytoprotection. NP-SH implements their gastroprotection effect by maintaining the integrity of the mucosal layer. Moreover, NP-SH has antioxidant properties as they attach to the liberated ROS from the deleterious agents such as ethanol..$^{53}$ The more extensive gastric tissue damage is always associated with diminished levels of NP-SH compounds. In this way, we evaluated the probable participation of NP-SH in the gastroprotective effect of BM. The gastric tissue homogenate of the rats pretreated with BM showed a significant increase in NP-SH level, which may be attributed to its gastroprotection and antioxidant actions.

HSP70 are essential proteins in the maintenance of cellular normal physiological function throughout the growth phase. ${ }^{54}$ However, HSP70 are also induced and commonly overexpressed in response to the noxious stimuli such as oxidative stress. A previous study proved the essential role of HSP70 in the mucosal cytoprotection. ${ }^{55}$ This effect may be prompted via the inhibition of the cell apoptotic process ${ }^{56}$ through its chaperone function, other than that of the immune response. ${ }^{57}$ An earlier study reported the critical involvement of HSP70 protein in the gastroprotection mechanisms against ethanol-induced gastric ulcer. ${ }^{58}$ Thus, for further mechanistic study, immunohistochemical staining for HSP70 localization was performed, and the results show that BM enhanced HSP70 expression into the pretreated animal tissue, suggesting the possible involvement of HSP70 in the gastroprotective action of BM.

BAX protein is a proapoptotic protein belonging to the Bcl-2 family, which has an essential role in the control of cellular apoptotic process. ${ }^{59} \mathrm{BAX}$ proteins are ordinarily located in the cellular cytosol. However, during the apoptosis process, those proteins shift toward the mitochondria ${ }^{60}$ Ethanol administration increases the production and the accumulation of ROS, which in turn upregulate BAX protein expression and result in acute ulcer formation to the gastric tissue.$^{15}$ In this study, antiapoptotic action was evaluated by the immunohistochemical localization of Bax proteins. The results suggest a possible involvement of antiapoptotic effect as the gastroprotective mechanism of BM against ethanol ulcer model.

H. pylori is a spiral-shaped Gram-negative bacterium, one of the most prevalent bacterial infections that affect many people worldwide. The bacterium is considered to be the main aggressive factor of peptic ulcer disease, and in most cases is related to the development of gastric carcinoma. It is expected that a patient who is diagnosed with H. pylori infection has a $10 \%-20 \%$ risk for that infection to progress to ulcer disease ${ }^{61}$ In accordance with the international guidelines, there are two protocols for $H$. pylori eradication; the first line is the triple regimen that is composed by either the proton pumping inhibitor or ranitidine bismuth citrate plus any two antibiotics of amoxicillin, clarithromycin, or metronidazole, and the second line is the regimen that is composed by the proton pump inhibitor, bismuth salts, tetracycline, and metronidazole. Despite the efficacy of H. pylori therapies, in many cases the eradication has not been achieved due to the aggravation of bacterial resistance problem or the accompanied side effects. For that reason, there is an increasing need to explore a new therapy with potent antibacterial activity with less or no side effects. ${ }^{62}$ Many natural agents from medicinal plants have implemented significant anti-H. pylori properties. ${ }^{63}$ A previous study considered that a compound which results in MIC value of $\leq 250 \mu \mathrm{g}$ / $\mathrm{mL}$ will exhibit stronger antibacterial activity. ${ }^{64}$ Thus, for further antiulcer study, the antibacterial effect of BM was examined against $H$. pylori through the microtiter dilution method. The result shows an interesting MIC value, which indicates the valuable effect of $\mathrm{BM}$ as gastroprotective and anti-H. pylori agent.

\section{Conclusion}

To sum up, the present data in this study revealed that BM from C. arborescens demonstrated significant gastroprotective activity against ethanol ulcer model in rats. The present gastroprotective activity of BM might be related to increased gastric mucosal protective mechanisms, particularly by its participation in free radical scavenging, stimulation of HSP70 expression, and enhancement of gastric mucusproduction effect. In addition, there is evidence which shows possible involvement of NP-SH and antiapoptotic action. The observed gastroprotection effect of BM was accomplished by significant antisecretory and interesting anti-H. pylori that may augment its antiulcer activity. Thus, $\mathrm{BM}$ can be seen as a promising gastroprotective agent and 
the presented data is of great value in paving the way for the future development of a antiulcer drug with high efficacy and a wide safety margin.

\section{Acknowledgments}

The authors would like to express their utmost gratitude and appreciation to University of Malaya (PG151-2012B) and to the Ministry of Higher Education Malaysia under High Impact Research grant (UM-MOHE UM.C/625/1/HIR/ $\mathrm{MOHE} / \mathrm{SC} / 09$ ) for providing a grant to conduct this study.

\section{Disclosure}

The authors report no conflicts of interest in this work.

\section{References}

1. de Souza Almeida ES, Filho VC, Niero R, Clasen BK, Balogun SO, de Oliveira Martins DT. Pharmacological mechanisms underlying the antiulcer activity of methanol extract and canthin-6-one of Simaba ferruginea A. St-Hil. in animal models. J Ethnopharmacol. 2011;134:630-636.

2. Potrich FB, Allemand A, da Silva LM, et al. Antiulcerogenic activity of hydroalcoholic extract of Achillea millefolium L.: involvement of the antioxidant system. J Ethnopharmacol. 2010;130(1):85-92.

3. Rozza AL, Moraes TM, Kushima H, et al. Gastroprotective mechanisms of Citrus lemon (Rutaceae) essential oil and its majority compounds limonene and $\beta$-pinene: involvement of heat-shock protein-70; vasoactive intestinal peptide; glutathione; sulfhydryl compounds; nitric oxide and prostaglandin $\mathrm{E}_{2}$. Chem Biol Interact. 2011;189(1):82-89.

4. de Lira Mota KS, Dias GEN, Pinto MEF, et al. Flavonoids with gastroprotective activity. Molecules. 2009;14(3):979-1012.

5. Schmeda-Hirschmann G, Yesilada E. Traditional medicine and gastroprotective crude drugs. J Ethnopharmacol. 2005;100(1):61-66.

6. Pedraza-Chaverri J, Cárdenas-Rodríguez N, Orozco-Ibarra M, PérezRojas JM. Medicinal properties of mangosteen (Garcinia mangostana). Food Chem Toxicol. 2008;46(10):3227-3239.

7. Sidahmed H, Abdelwahab SI, Mohan S, et al. $\alpha$-Mangostin from Cratoxylum arborescens (Vahl) Blume demonstrates anti-ulcerogenic property: a mechanistic study. Evid Based Complement Alternat Med. 2013;2013:450840.

8. Syam S, Bustamam A, Abdullah R, et al. $\beta$-Mangostin induces p53dependent G2/M cell cycle arrest and apoptosis through ROS mediated mitochondrial pathway and NfkB suppression in MCF-7 cells. J Funct Foods. 2014;6(0):290-304.

9. Sidahmed HM, Azizan AH, Mohan S, et al. Gastroprotective effect of desmosdumotin $\mathrm{C}$ isolated from Mitrella kentii against ethanolinduced gastric mucosal hemorrhage in rats: possible involvement of glutathione, heat-shock protein-70, sulfhydryl compounds, nitric oxide, and anti-Helicobacter pylori activity. BMC Complement Altern Med. 2013;13(1):183.

10. Shay H. A simple method for the uniform production of gastric ulceration in the rat. Gastroenterology. 1945;5:43-61.

11. Rao CV, Vijayakumar M. Effect of quercetin, flavonoids and $\alpha-$ tocopherol, an antioxidant vitamin on experimental reflux oesophagitis in rats. Eur J Pharmacol. 2008;589(1-3):233-238.

12. Njar VC, Adesanwo JK, Raji Y. Methyl angolensate: the antiulcer agent of the stem bark of Entandrophragma angolense. Planta Med. 1995; 61(01):91-92.

13. Tan PV, Nyasse B, Dimo T, Mezui C. Gastric cytoprotective anti-ulcer effects of the leaf methanol extract of Ocimum suave (Lamiaceae) in rats. J Ethnopharmacol. 2002;82(2):69-74.

14. Taha MME, Salga MS, Ali HM, Abdulla MA, Abdelwahab SI, Hadi AHA. Gastroprotective activities of Turnera diffusa Willd. ex Schult. revisited: role of arbutin. J Ethnopharmacol. 2012;141(1): 273-281.
15. Sidahmed H, Hashim NM, Amir J, et al. Pyranocycloartobiloxanthone A, a novel gastroprotective compound from Artocarpus obtusus Jarret, against ethanol-induced acute gastric ulcer in vivo. Phytomedicine. 2013; 20(10):834-843.

16. Chen H, Liao H, Liu Y, et al. Protective effects of pogostone from Pogostemonis Herba against ethanol-induced gastric ulcer in rats. Fitoterapia. 2015;100(0):110-117.

17. Behmer OA. Manual de técnicas para histologia normal e patológica. EDART/USP; 1976.

18. Laine L, Weinstein WM. Histology of alcoholic hemorrhagic "gastritis": a prospective evaluation. Gastroenterology. 1988;94(6):1254-1262.

19. Bandyopadhyay U, Biswas K, Chatterjee R, et al. Gastroprotective effect of Neem (Azadirachta indica) bark extract: possible involvement of $\mathrm{H}^{+}-\mathrm{K}^{+}$-ATPase inhibition and scavenging of hydroxyl radical. Life Sci. 2002;71(24):2845-2865.

20. Hiruma-Lima CA, Gracioso JS, Bighetti EJB, Grassi-Kassisse DM, Nunes DS, Souza Brito ARM. Effect of essential oil obtained from Croton cajucara Benth. on gastric ulcer healing and protective factors of the gastric mucosa. Phytomedicine. 2002;9(6):523-529.

21. Poonam D, Vinay CS, Gautam P. Cyclo-oxygenase-2 expression and prostaglandin $\mathrm{E}_{2}$ production in experimental chronic gastric ulcer healing. Eur J Pharmacol. 2005;519(3):277-284.

22. Rahman I, Kode A, Biswas SK. Assay for quantitative determination of glutathione and glutathione disulfide levels using enzymatic recycling method. Nat Protoc. 2007;1(6):3159-3165.

23. Hodges DM, DeLong JM, Forney CF, Prange RK. Improving the thiobarbituric acid-reactive-substances assay for estimating lipid peroxidation in plant tissues containing anthocyanin and other interfering compounds. Planta. 1999;207(4):604-611.

24. Beauchamp C, Fridovich I. Superoxide dismutase: improved assays and an assay applicable to acrylamide gels. Anal Biochem. 1971;44(1): 276-287.

25. Benzie IF, Strain J. The ferric reducing ability of plasma (FRAP) as a measure of "antioxidant power": the FRAP assay. Anal Biochem. 1996; 239(1):70-76.

26. Sedlak J, Lindsay RH. Estimation of total, protein-bound, and nonprotein sulfhydryl groups in tissue with Ellman's reagent. Anal Biochem. 1968;25(1):192-205.

27. Jorgensen JH, Hindler JF, Reller LB, Weinstein MP. New consensus guidelines from the Clinical and Laboratory Standards Institute for antimicrobial susceptibility testing of infrequently isolated or fastidious bacteria. Clin Infect Dis. 2007;44(2):280-286.

28. Malfertheiner P, Chan FK, McColl KE. Peptic ulcer disease. Lancet. 2009;374(9699):1449-1461.

29. Borrelli F, Izzo AA. The plant kingdom as a source of anti-ulcer remedies. Phytother Res. 2000;14(8):581-591.

30. Brodie DA. The mechanism of gastric hyperacidity produced by pylorus ligation in the rat. Am J Dig Dis. 1966;11(3):231-241.

31. Mahmood A, Sidik K, Salmah I, Suzainor K, Philip K. Antiulcerogenic activity of Ageratum conyzoides leaf extract against ethanol-induced gastric ulcer in rats as animal model. Int J Mol Med Adv Sci. 2005;1(4): 402-405.

32. Kvietys P, Twohig B, Danzell J, Specian R. Ethanol-induced injury to the rat gastric mucosa. Role of neutrophils and xanthine oxidase-derived radicals. Gastroenterology. 1990;98(4):909-920.

33. Massignani JJ, Lemos M, Maistro EL, et al. Antiulcerogenic activity of the essential oil of Baccharis dracunculifolia on different experimental models in rats. Phytother Res. 2009;23(10):1355-1360.

34. Repetto M, Llesuy S. Antioxidant properties of natural compounds used in popular medicine for gastric ulcers. Braz J Med Biol Res. 2002; 35(5):523-534.

35. Samonina G, Kopylova G, Lukjanzeva G, et al. Antiulcer effects of amylin: a review. Pathophysiology. 2004;11(1):1-6.

36. Sidahmed HMA, Azizan AHS, Mohan S, et al. Gastroprotective effect of desmosdumotin C isolated from Mitrella kentii against ethanol-induced gastric mucosal hemorrhage in rats: possible involvement of glutathione, heat-shock protein-70, sulfhydryl compounds, nitric oxide, and anti-Helicobacter pylori activity. BMC Complement Altern Med. 2013;13(1):183. 
37. Laine L, Takeuchi K, Tarnawski A. Gastric mucosal defense and cytoprotection: bench to bedside. Gastroenterology. 2008;135(1):41-60.

38. Santin JR, Lemos M, Júnior LCK, Niero R, de Andrade SF. Antiulcer effects of Achyrocline satureoides (Lam.) DC (Asteraceae) (Marcela), a folk medicine plant, in different experimental models. J Ethnopharmacol. 2010;130(2):334-339.

39. Szabo S, Trier J, Brown A, Schnoor J. Early vascular injury and increased vascular permeability in gastric mucosal injury caused by ethanol in the rat. Gastroenterology. 1985;88(1 Pt 2):228-236.

40. Iijima K, Ichikawa T, Okada S, et al. Rebamipide, a cytoprotective drug, increases gastric mucus secretion in human: evaluations with endoscopic gastrin test. Dig Dis Sci. 2009;54(7):1500-1507.

41. Banerjee D, Bauri AK, Guha RK, Bandyopadhyay SK, Chattopadhyay S. Healing properties of malabaricone $\mathrm{B}$ and malabaricone $\mathrm{C}$, against indomethacin-induced gastric ulceration and mechanism of action. Eur J Pharmacol. 2008;578(2):300-312.

42. Jesus NZT, Falcão HS, Lima GRM, et al. Hyptis suaveolens (L.) Poit (Lamiaceae), a medicinal plant protects the stomach against several gastric ulcer models. J Ethnopharmacol. 2013;150(3):982-988.

43. Cnubben NH, Rietjens IM, Wortelboer H, van Zanden J, van Bladeren PJ. The interplay of glutathione-related processes in antioxidant defense. Environ Toxicol Pharmacol. 2001;10(4):141-152.

44. Tamagno E, Aragno M, Boccuzzi G, et al. Oxygen free radical scavenger properties of dehydroepiandrosterone. Cell Biochem Funct. 1998; 16(1):57-63.

45. Fesharaki M, Nasimi A, Mokhtari S, Mokhtari R, Moradian R, Amirpoor N. Reactive oxygen metabolites and anti-oxidative defenses in aspirin-induced gastric damage in rats: gastroprotection by vitamin E. Pathophysiology. 2006;13(4):237-243.

46. Fattman CL, Schaefer LM, Oury TD. Extracellular superoxide dismutase in biology and medicine. Free Radic Biol Med. 2003;35(3):236-256.

47. Halliwell B. How to characterize a biological antioxidant. Free Radic Res. 1990;9(1):1-32

48. Grant CM. Role of the glutathione/glutaredoxin and thioredoxin systems in yeast growth and response to stress conditions. Mol Microbiol. 2001; 39(3):533-541.

49. Morais TC, Pinto NB, Carvalho KM, et al. Protective effect of anacardic acids from cashew (Anacardium occidentale) on ethanol-induced gastric damage in mice. Chem Biol Interact. 2010;183(1):264-269.

50. Bilici D, Süleyman H, Banoğlu ZN, et al. Melatonin prevents ethanolinduced gastric mucosal damage possibly due to its antioxidant effect. Dig Dis Sci. 2002;47(4):856-861.
51. Chakraborti A, Gulati K, Banerjee BD, Ray A. Possible involvement of free radicals in the differential neurobehavioral responses to stress in male and female rats. Behav Brain Res. 2007;179(2):321-325.

52. Tachakittirungrod S, Okonogi S, Chowwanapoonpohn S. Study on antioxidant activity of certain plants in Thailand: mechanism of antioxidant action of guava leaf extract. Food Chem. 2007;103(2):381-388.

53. Szabo S, Vattay P. Experimental gastric and duodenal ulcers. Advances in pathogenesis. Gastroenterol Clin North Am. 1990;19(1):67-85.

54. Mei X, Xu D, Xu S, Zheng Y, Xu S. Gastroprotective and antidepressant effects of a new zinc (II)-curcumin complex in rodent models of gastric ulcer and depression induced by stresses. Pharmacol Biochem Behav. 2011;99(1):66-74.

55. Rokutan K. Role of heat shock proteins in gastric mucosal protection. J Gastroenterol Hepatol. 2000;15(s1):12-19.

56. Golbabapour S, Gwaram NS, Al-Obaidi MMJ, Soleimani A, Ali HM, Abdul Majid N. Schiff base metal derivatives enhance the expression of HSP70 and suppress BAX proteins in prevention of acute gastric lesion. Biomed Res Int. 2013;2013:703626.

57. Mosser DD, Caron AW, Bourget L, et al. The chaperone function of hsp70 is required for protection against stress-induced apoptosis. Mol Cell Biol. 2000;20(19):7146-7159.

58. Tsukimi Y, Okabe S. Recent advances in gastrointestinal pathophysiology: role of heat shock proteins in mucosal defense and ulcer healing. Biol Pharm Bull. 2001;24(1):1-9.

59. Strobel T, Swanson L, Korsmeyer S, Cannistra SA. BAX enhances paclitaxel-induced apoptosis through a p53-independent pathway. Proc Natl Acad Sci. 1996;93(24):14094-14099.

60. Wolter KG, Hsu Y-T, Smith CL, Nechushtan A, Xi X-G, Youle RJ. Movement of Bax from the cytosol to mitochondria during apoptosis. J Cell Biol. 1997;139(5):1281-1292.

61. Kusters JG, van Vliet AH, Kuipers EJ. Pathogenesis of Helicobacter pylori infection. Clin Microbiol Rev. 2006;19(3):449-490.

62. Di Mario F, Cavallaro LG, Scarpignato C. 'Rescue'therapies for the management of Helicobacter pylori infection. Dig Dis. 2006; 24(1-2):113-130.

63. Castillo-Juárez I, Rivero-Cruz F, Celis H, Romero I. Anti-Helicobacter pylori activity of anacardic acids from Amphipterygium adstringens. J Ethnopharmacol. 2007;114(1):72-77.

64. Moraes TdM, Rodrigues CM, Kushima H, et al. Hancornia speciosa: indications of gastroprotective, healing and anti-Helicobacter pylori actions. J Ethnopharmacol. 2008;120(2):161-168.

\section{Publish your work in this journal}

Drug Design, Development and Therapy is an international, peerreviewed open-access journal that spans the spectrum of drug design and development through to clinical applications. Clinical outcomes, patient safety, and programs for the development and effective, safe, and sustained use of medicines are a feature of the journal, which

\section{Dovepress}

has also been accepted for indexing on PubMed Central. The manuscript management system is completely online and includes a very quick and fair peer-review system, which is all easy to use. Visit http://www.dovepress.com/testimonials.php to read real quotes from published authors. 